\title{
Membrane potential regulates the dynamic localisation of mammalian proteasomes
}

Yu Zhang ${ }^{1}$, Anna Helena Lippert ${ }^{1}$, Ji Eun Lee ${ }^{1}$, Alexander Roy Carr ${ }^{1}$, Aleks Ponjavic ${ }^{1}$, Steve F Lee ${ }^{1}$, Daniel Finley ${ }^{2 \$}$, David Klenerman ${ }^{1 \$}, \mathrm{Yu} \mathrm{Ye}^{1,2 * \$}$

${ }^{1}$ Department of Chemistry, University of Cambridge, Lensfield Road, Cambridge CB2 1EW, UK

${ }^{2}$ Department of Cell Biology, Harvard Medical School, Longwood Avenue, Boston 02115

\$Correspondence to yy308@cam.ac.uk, dk10012@cam.ac.uk or

daniel finley@hms.harvard.edu

*These authors contributed equally to the manuscript

Word count: 3172

Running title: Dynamic localisation of mammalian proteasomes in cells 


\begin{abstract}
$\underline{\text { Abstract }}$
Proteasomes are molecular machineries responsible for regulated protein degradation and general homeostasis. The distribution of this degradation capacity is reflected by the cellular localisation of proteasomal particles. Here we combine super-resolution imaging, single-particle tracking (SPT) and single-cell patch clamp techniques to investigate the localisation and translocation of endogenous mammalian proteasomes tagged with fluorescent proteins. While proteasomes are found dispersed in the cell without distinct localisation, we detect a higher density of proteasomes in the nucleus compared to the ER and the cytosol. SPT of proteasomes revealed two populations with diffusion coefficients averaging $\sim 4$ and $\sim 0.8 \mu \mathrm{m}^{2} / \mathrm{s}$. The ratio between these two populations could be altered upon changed cellular conditions. We further report that proteasomal particles translocate to the cell periphery during hyperpolarisation, while depolarisation re-localises proteasomes to the cell interior. Depolymerising microtubules or actin filaments inhibited this potential-dependent translocation. Our results suggest that at resting membrane potential proteasomes undergo diffusion-based motions, while membrane polarisation may induce cytoskeleton-dependent translocation. Fine-tuning these translocation modes can potentially dedicate proteasomes to degradation activities at distinct subcellular sites. (173 words)
\end{abstract}

\title{
$\underline{\text { Introduction }}$
}

The Ubiquitin-Proteasome system is responsible for selective protein degradation in cells, and regulates many key biological processes including DNA repair, cell cycle and homeostasis ${ }^{1-3}$. Proteasomes constitute $\sim 1 \%$ of the mammalian proteome and are considered the main molecular degradation machinery in cells ${ }^{4}$. The $26 \mathrm{~S}$ proteasome holoenzyme consists of a 20S core particle (CP) capped at one or both ends with 19S regulatory particles $(\mathrm{RP})^{5,6}$. The CP contains several proteolytic enzymes that cleave unfolded proteins into short peptides, while substrate recognition and unfolding are carried out by subunits of the $\mathrm{RP}^{7,8,9}$. In cells, the holoenzyme may reversibly assemble from free CPs and $\mathrm{RPs}^{4}$. Individual proteasomes may further assemble reversibly into distinct bodies inside the cell under certain physiological conditions ${ }^{10,11,12}$; in particular they may associate with aggregates of misfolded proteins $^{12}$. 
While cellular proteasomes are dynamic, quantification of proteasomal motions remains elusive. One early study reported proteasomes to diffuse slowly in cells (diffusion coefficient $\left.<0.5 \mu \mathrm{m}^{2} / \mathrm{s}\right)^{13}$. This was amended by a more recent study in yeast cells expressing $\mathrm{CP}$ and RP subunits genetically tagged with fluorescent proteins (FP), and showed a fast- as well as a slowly-diffusing proteasome population in both the nucleus and the cytoplasm ${ }^{14}$. To date, no direct tracking of individual endogenous proteasomal particles has been performed in live mammalian cells.

Various subcellular localisations of proteasomes have been reported, depending on the type of cells, method of fixation and imaging technique used ${ }^{15-18}$. Early imaging studies on immunostained mammalian cells found that proteasomes preferentially localised to the $\mathrm{ER} /$ nuclear envelope ${ }^{19,20}$. In yeast cells, the majority of proteasomal particles were found in the nucleus ${ }^{21}$. Additional studies have suggested that yeast and mammalian proteasomes may be imported from the cytosol into the nucleus (e.g. ${ }^{22,23}$ ), and that proteasomal localisation could be dependent on the stage of the cell cycle ${ }^{15,21,24}$. A seminal study showed, by overexpressing a GFP-tagged RP subunit in neurons, that proteasomes translocated to synaptic spines upon membrane depolarisation, thus increasing local degradation activity ${ }^{25}$. Recently, EM imaging of immunostained neurons further revealed a predominant $\mathrm{CP}$ localisation to the plasma membrane, which was distinct from their preferred cytosolic localisation in HEK cells ${ }^{26}$. Given that previous work has been carried out on fixed cells or through overexpressing fluorescently tagged proteasomal subunits, the use of live mammalian cells expressing endogenously tagged subunits may enable studies on the dynamics in proteasomal localisation in real-time.

In this work, we used 2D total-internal fluorescence reflection microscopy (TIRF) and 3D single-molecule localisation microscopy (SMLM) with a double-helix point-spread function (DHPSF) to study the localisation of proteasomes in HEK cells. Proteasomal particles were found dispersed throughout the cell, with highest density in the nucleus. We further implemented 2D single-particle tracking (SPT) of individual proteasomal particles, and detected two populations that diffuse either fast $\left(D_{\text {fast }} \sim 4 \mu \mathrm{m}^{2} / \mathrm{s}\right)$ or slowly $\left(D_{\text {slow }} \sim 0.8 \mu \mathrm{m}^{2} / \mathrm{s}\right)$. Combining TIRF imaging with patch-clamp techniques, we showed that hyperpolarisation of membrane potential induced accumulation of proteasomal particles at the cell periphery, while depolarisation caused these particles to move away from the cell surface to the interior 
of the cell. This potential-induced and reversible transport of proteasomes was lost in the presence of microtubule- or actin-depolymerising drugs. In contrast, depolymerising either cytoskeletal proteins had no effect on the diffusion coefficients of proteasomal particles at resting membrane potential. Therefore, transport of proteasomes between the cell periphery and the interior appears to be dependent on the proper assembly of the cytoskeleton, which is a distinct mechanism from random diffusion of proteasomal particles at resting membrane potential. Together, our data suggest that cellular translocation of proteasomal particles at resting membrane potential is largely through diffusive movements, while changes in the potential are able to also induce directional transport of proteasomes through the cytoskeleton.

\section{$\underline{\text { Results }}$}

\section{Proteasomal particles are densely localised inside the nucleus of mammalian cells}

To study the dynamics of proteasomal localisation in live mammalian cells, we used CRISPR-Cas9 gene editing techniques to establish HEK293A (HEK) cell lines endogenously expressing either Rpn11 or Pre1, subunits of the RP and CP, respectively, fused to a FP (eGFP or mEos) at the C-terminus (see Materials and Methods). The C-termini of both Rpn11 and Pre1 have been routinely tagged with FP and other protein domains for purification of proteasomal particles and for studies on proteasome activity and localisation ${ }^{11,24,27}$. Biochemical analysis of the four transgenic cell lines (Rpn11-eGFP, Rpn11-mEos, Pre1-eGFP or Pre1-mEos; modifications confirmed by genotyping and Western blots) showed that the genetically modified Rpn11 and Pre1 were not detected in the lysate but co-immunoprecipitated with other proteasomal subunits, suggesting full incorporation into the RP and CP, respectively (SFigure 1). All cell lines we used in this study are expanded from single cells (monoclonal) and expressing both unmodified and FPmodified proteasomal subunits (heterogeneous), which enabled the FP to be detected at a suitable level for in vivo single-molecule imaging.

Early imaging studies found that a significant proportion of the proteasome holoenzyme was localised to the ER in immunostained HEK cells ${ }^{19,28,29}$, perhaps since proteasomes serve as the end destination for substrates of ER-mediated degradation ${ }^{30}$ (reviewed in $\left[{ }^{31}\right]$ ). We therefore first investigated the distribution profile of proteasomes in cells expressing transgenic Rpn11-mEos or Pre1-mEos using super-resolution microscopy. To determine the proportion of proteasomes localised to the ER, we expressed a plasmid 
encoding eGFP-sec61 in the transgenic cell lines ${ }^{32}$. Cells were fixed prior to sequential image acquisition of fluorescence emission from photo-converted mEos followed by from eGFPsec61 (Figure 1a and b). Our microscope was set up to image the cell interior in HILO mode $^{33}$ where fluorescence from eGFP-sec61 was clearly visible. Stochastic blinking of photo-converted mEos enabled us to perform fluorescence photo-activated localisation microscopy (fPALM) analysis (see Materials and Methods) with $\sim 16 \mathrm{~nm}$ precision (SFigure 2). Using this approach, we quantified the fraction of individual mEos signals that overlapped with the ER (eGFP-sec61) in 2D, in the nucleus that is surrounded by the ER, or in the cytosol where no ER signal is detected (SFigure 3). Both Rpn11-mEos and Pre1-mEos were found at a higher density in the nucleus compared to in the ER/cytosol ( 3- and $~ 2$-fold higher, respectively), suggesting that the concentrations of RP and CP are relatively higher inside the nucleus (Figure 1c).

Visualisation in 3D with a microscope dedicated for DHPSF imaging (detecting localisations over a $\sim 4 \mu \mathrm{m}$ axial range) showed an apparent higher density of Rpn11-mEos and Pre1-mEos signals in the central regions of the cell as compared to peripheral regions, further suggesting a higher proteasomal density inside the nucleus (SFigure 4). Proteasomal particles are dispersed throughout the cytoplasm and nucleoplasm, but excluded from the nucleoli and certain nuclear bodies, consistent with previous reports (e.g. $\left.{ }^{15,34}\right)$. ER colocalisation experiments were not conducted in 3D due to a lack of suitable SMLM probes for ER labelling. In all cells analysed both in 2D and in 3D, individual Pre1-mEos and Rpn11-mEos signals appeared to be distributed within the nucleus and the cytosol, with decreasing abundance towards the cell periphery (SFigure 3). We could not detect any significant clustering of fluorescence signals, which would have suggested preferred subcellular localisation or the presence of large proteasomal assemblies. Together, these results suggest that proteasomal particles are dispersed in both the cytoplasm and the nucleoplasm, with more proteasomes found in the cell interior than proximal to the cell periphery.

\section{Two distinct diffusion populations of proteasomal particles}

The lack of distinct subcellular localisation and accumulation of fluorescence signals suggest that proteasomal particles may be highly dynamic and moving freely within the cell. To verify this, we performed SPT in live transgenic cells expressing either Rpn11 or Pre1 fused 
to eGFP, which fluoresces continuously without stochastic blinking. Movements of individual eGFP signals were tracked in TIRF mode to preferentially illuminate the cellular region within the evanescent field up to $\sim 200 \mathrm{~nm}$ from the coverslip (cell periphery). For Rpn11-eGFP, we could observe two distinct populations of molecules diffusing at different rates in the cell, one apparently much faster than the other (tracking of two Rpn11-eGFP signals are shown in Figure 2a and SVideo 1).

The diffusion coefficients $(D)$ of the two populations were determined by considering the distance covered by each individual molecule between consecutive image frames (Jump Distance, $J D$, see Materials and Methods). The $J D$ values of individual tracks from each cell were separately fitted as previously described ${ }^{35}$. In cells expressing Rpn11-eGFP, a fastand a slow-moving ( $D_{\text {fast }}$ at $3.7 \pm 1.0 \mu \mathrm{m}^{2} / \mathrm{s}$ and $D_{\text {slow }}$ at $0.8 \pm 0.2 \mu \mathrm{m}^{2} / \mathrm{s}, \mathrm{n}=14$ cells) diffusion population were identified (Figure $\mathbf{2 b}$ and SVideo 2) with roughly equal abundance $\left(54 \% \pm 8 \%\right.$ are $\left.D_{\text {fast }}\right)$, suggesting that there are two diffusion coefficients for the RP. Two populations at similar ratios $\left(49 \% \pm 9 \% D_{\text {fast }}\right)$ were also observed in cells expressing Pre1eGFP, which had comparable $D_{\text {fast }}$ and $D_{\text {slow }}$ values $\left(4.1 \pm 1.2 \mu \mathrm{m}^{2} / \mathrm{s}\right.$ and $0.8 \pm 0.2 \mu \mathrm{m}^{2} / \mathrm{s}$, respectively; $\mathrm{n}=16$, Figure $2 \mathrm{c}$ and SVideo 2) to those of Rpn11-eGFP. Our $D_{\text {fast }}$ values suggest that roughly half of cellular proteasomal particles appear to be freely diffusing, while $D_{\text {slow }}$ values are comparable to expected values for proteins associated with cellular structures or membranes. Both populations have been observed in previous FCS measurements in yeast cells with similar interpretations of the populations ${ }^{14}$.

Proteasomes have been shown to reversibly assemble into foci (e.g. PSGs, aggrosomes, and proteasomal clusters/“clastosomes") for dedicated cellular functions ${ }^{10}$. We suspected that assembly into such cellular bodies would reduce proteasomal movement by diffusion and followed previous protocols ${ }^{10}$ to induce "clastosomes" in mammalian cells with a hypertonic solution(SVideo 3). TIRF imaging showed a slow-down of proteasomal particles immediately after treatment with a hypertonic solution $\left(D_{\text {fast }}\right.$ reduced from $\sim 4$ to $\sim 2$ $\mu \mathrm{m}^{2} / \mathrm{s}$ and $D_{\text {slow }}$ from 0.8 to $0.5 \mu \mathrm{m}^{2} / \mathrm{s}, \mathrm{n}=13$ cells for both Rpn11-mEos and Pre1-mEos. SFigure 5). Notably, a lower proportion of proteasomes are fast-moving ( 38\%), suggesting that "clastosome" formation results in more proteasomes to assume the behaviour of the slow-diffusing population.

To confirm that the diffusion coefficients and populations were not restricted to proteasomal particles at the cell periphery, we repeated imaging in HILO mode and found no 
obvious change in the diffusion coefficients (SFigure 6), confirming the presence of two distinct diffusion rates of endogenous proteasomes in live cells. $J D$ values from multiple cells were combined due to a higher rate of photo-bleaching associated with HILO imaging. We further determined the diffusion coefficients of eGFP-tagged USP21 as a control, to rule out that the fast-moving population was due to dissociation of the tagged subunit from the particle. USP21 is a mostly cytosolic protein of similar size to Rpn11 and related to the ubiquitin-system but does not stably form part of any known protein complex ${ }^{36}$. Accordingly, we detected a significantly higher $D_{\text {fast }}\left(11 \pm 1.0 \mu \mathrm{m}^{2} / \mathrm{s}\right)$ as well as $D_{\text {slow }}\left(1.5 \pm 0.2 \mu \mathrm{m}^{2} / \mathrm{s}\right.$, $)$, where the majority (>60\%) of USP21-eGFP are fast-moving (SFigure 7, $\mathrm{n}=8$ cells; and SVideo 4).

\section{Membrane potential induces proteasomal translocation to and from the cell periphery}

Proteasomes in rat hippocampal neurons were reported in a previous study to relocalise and increase the local degradation activity in synaptic spines upon membrane depolarisation ${ }^{25}$. We therefore tested whether changes in membrane potential may be exploited to regulate proteasome localisation and orchestrate proteasomal movements inside the cell. To modulate proteasome movements, we combined single-cell patch-clamp with TIRF imaging of transgenic Rpn11-eGFP or Pre1-eGFP cells. A lower laser power was used for TIRF illumination to reduce the rate of eGFP photo-bleaching during patch-clamp experiments. The resting membrane potential was found to be around $-20 \mathrm{mV}$, consistent with published values for HEK cells (e.g. $\left[{ }^{37,38}\right]$ ). The membrane potential was then clamped on cells expressing Pre1-eGFP and oscillated between depolarisation $(+100 \mathrm{mV})$ and hyperpolarisation (-100 mV) (SFigure 8, $\mathrm{n}=14$ cells). Under TIRF illumination, we found that during hyperpolarisation Pre1-eGFP signals accumulated close to the cell periphery (i.e. within the evanescent field and hence detected by TIRF illumination), while every depolarisation event resulted in a drop of the detected fluorescence intensity, suggestive of proteasome translocation into the cell interior (Figure 3a and b, SVideo 5; oscillation in potential every $60 \mathrm{~s}$ ). The characteristic periodic change in fluorescence intensity with the oscillating potential can be detected across the voltage-clamped cell, while the unclamped neighbouring cells were unaffected ( $\mathrm{C} 1$ and $\mathrm{C} 2$ cells, Figure 3a). We did not observe any morphological changes of the cell during patch-clamp under our experimental conditions. 
To further demonstrate that the change in fluorescence intensity is dependent on the clamped voltage, we set the oscillation time to $30 \mathrm{~s}$ and repeated the measurement in Rpn11eGFP cells, which also resulted in periodic changes in fluorescence intensity with the potential oscillations (Figure 3c,e and SVideo 6). This confirms that the reversible movement of eGFP-signals into and out of the evanescent field is dependent on the clamped voltage. In comparison, eGFP-tagged USP21, which has not been reported to associate with the proteasome, did not respond to changes in membrane potential under the same experimental conditions (Figure 3d,e and SVideo 7). The magnitude of fluorescence oscillation from repeated measurements of eGFP-tagged Rpn11 and Pre1 confirmed that the reversible translocation effect cannot be attributed to the free forms of these proteins, but rather reflects the behaviour of reporters that have properly incorporated into the proteasome (Figure 3f). We further verified that the potential-induced proteasome translocation occurs at the cell periphery by repeating the voltage-clamp experiment in HILO mode. Using HILO illumination of the whole cell, we detected periodic changes in fluorescence intensity of Pre1eGFP at the cell periphery ( $\boldsymbol{P}$, SFigure 9), while no significant change was detected in the cell interior or the adjacent control cell ( $\boldsymbol{M}$ and $\boldsymbol{C}$, respectively, SFigure 9).

These experiments together suggest that localisation of both the proteasomal $\mathrm{CP}$ and the RP are reversibly modulated through the membrane potential. Proteasomal particles are transported between the cell periphery and interior during hyper- or depolarisation, respectively. These events are clearly detectable under TIRF illumination, in contrast to the diffusive proteasome movements at resting membrane potential. Such directed and reversible translocation of proteasomes is suggestive of active transport along the cytoskeleton.

\section{Potential-induced proteasome translocation is dependent on the cytoskeleton}

Since the reversible movement of proteasomal particles to and from the cell periphery appeared to be bi-directional depending on the membrane potential, we next tested the hypothesis that the cytoskeleton is involved in enabling such translocation of proteasomes. To address this, HEK cells expressing Pre1-eGFP were briefly incubated with Colcemid or Latrunculin A (LatA), which depolymerise microtubules or actin filaments, respectively, prior to the patch-clamp experiment. After 20 min treatment with Colcemid or LatA, hyperor depolarising the membrane potential no longer had any effect on the localisation of Pre1eGFP (Figure 4a), and the typical periodic changes in fluorescence intensity with the 
potential were lost (Figure 4c, top). In contrast, reversible proteasome translocation was retained in cells treated with vehicle controls (DMSO or EtOH, Figure 4b), and the fluorescence intensity expectedly oscillated with changes in the potential (Figure 4c, bottom). These results suggest that the loss of potential-dependent translocation was due to depolymerisation of the cytoskeleton.

Similar results were also observed in Rpn11-eGFP cells treated with Colcemid or LatA, which were comparable to the Pre1-eGFP cells with depolymerised cytoskeleton (Figure 4d), further indicating that both the $\mathrm{CP}$ and the RP are dependent on the cytoskeleton for transport (SVideo 8). Interestingly, we could not detect any obvious differences in the diffusion coefficients of Pre1-eGFP or Rpn11-eGFP even after prolonged incubation with either LatA or Colcemid (Figure 5). Thus, the cytoskeleton may only be involved in proteasomal transport induced by changes in membrane potential but does not affect their normal diffusive movement. Assembly of both microtubules and actin filaments appear to be necessary for the translocation of proteasomal particles between the cell periphery and the interior in a potential-dependent manner.

\section{$\underline{\text { Discussion }}$}

The localisation and motion of the $\mathrm{CP}$ and RP showed very similar behaviour in the current study. Both particles are densely localised in the nucleus, and appear to diffuse at two distinct rates independently of the assembly of microtubules or actin filaments. These observations suggest that holoenzymes could be the dominant form of proteasome assembly in mammalian cells, which has already previously been reported for yeast cells ${ }^{14}$. The values we determined for $D_{\text {fast }}$ and $D_{\text {slow }}$ by direct imaging are consistent with those obtained from FCS in yeast cells $^{14}$, though we cannot exclude possible transient interactions of the proteasome with the cytoskeleton or other cellular structures undetected by our method. Membrane hyper- or depolarisation is able to induce further translocation of the CP and the RP between the cell periphery and interior in a reversible manner, dependent on the cytoskeleton. Together, these results suggest a dynamic scenario of proteasomal movement inside the cell: at resting membrane potential proteasomes are largely diffusing independently of the cytoskeleton and dispersed throughout the cell; changes in the potential induce relocalisation of proteasomal particles, which are transported by the cytoskeleton to or away from the cell membrane. Additional studies on other cellular events that may affect proteasomal motion, e.g. through 
induction of proteasomal "clastosome" formation, may further complete this working model of proteasome translocation. The current work is, to our knowledge, the first study of mammalian proteasomes using endogenously tagged proteasome subunits.

Relocalisation of proteasomal particles has been previously reported in rat neurons, where depolarisation induced accumulation of proteasomes in an actin-dependent manner ${ }^{25}$. We showed here that in HEK cells, changes in the membrane potential induce proteasome translocation in a manner that depends on both microtubules and actin filaments. Previous mass spectroscopy studies in HEK cells have suggested potential molecular interactions of proteasomes with motor proteins as well as tubulin and $\operatorname{actin}^{39}$. Directional transport along the cytoskeleton would enable a rapid increase in proteasome level and thus local degradation activity, in response to changes in membrane potential. Intriguingly, only a subset of proteasomes appeared to be transported in both our and the previous study in rat neurons ${ }^{25}$. This suggests that other proteasomal particles remain dispersed through the cell to ensure that general protein turnover and homeostasis are not disrupted. Given that different cell types have distinct resting membrane potentials, proteasome localisation and movement might be very different between cell types and account for some of the reported differences (reviewed in $\left.\left[{ }^{17}\right]\right)$. Small changes in local proteasome level could therefore be sufficient to activate physiological processes sensitive to degradation. For instance, fluctuations in membrane potential are characteristic to the phases of the cell cycle ${ }^{40,41}$, a process during which the cell undergoes major changes in protein composition and cell morphology, both of which are critically regulated by proteasome-dependent degradation in a spatio-temporal manner ${ }^{42}$. It remains to be discovered in future studies whether other types of processes associated with changes in membrane potential, such as cell cycle, cell stress and neuronal membrane excitability, may result in similar proteasomal responses.

\section{Acknowledgement}

YY performed single-molecule tracking and fPALM imaging with help from JEL. YY, AHL and AP analysed the data for localisation and tracking. ARC and SFL built 3D the DHPSF microscope and ARC performed imaging experiments. YY and YZ performed patch-clamp experiments, which were analysed using codes written by AHL. YY, DK and DF directed the 
research. YY conceptualised the research, designed the experiments and prepared the manuscript.

\section{Materials and Methods}

\section{Transgenic cell lines}

Genomic sequences of mammalian RPN11 and PRE1 were modified at 3'-end of the last exon with CRISPR-cas9 genetic engineering system to replace the stop codon with DNA sequences coding for eGFP or mEos3.2. HEK293A (HEK) cells were co-transfected with a donor plasmid (encoding the FP sequence flanked by the homology arms of RPN11 or PRE1), gRNA plasmid (targeting the 3'-end of either RPN11 or PRE1 DNA sequence), and an SpCas9 expression plasmid. Clones expressing eGFP or mEos were individually sorted by fluorescence intensity and grown to confluency. Correct insertions of FP sequence into the genome was identified by PCR using primers based on the flanking sequences followed by sequencing of the PCR product. Cell lines deemed suitable for TIRF imaging were selected for subsequent experiments. Heterogeneous monoclonal cells encoding Rpn11-eGFP, Pre1eGFP, Rpn11-mEos or Pre1-mEos were used in this study.

\section{Co-immunoprecipitation of proteasome particles}

We confirmed incorporation of modified Rpn11 and Pre1 into proteasome particles by coimmunoprecipitation as previously described ${ }^{25}$. Briefly, cells were lysed using RIPA buffer and the cell lysate was cleared on a benchtop centrifuge for $10 \mathrm{~min}$. The supernatant was then first pre-incubated with Protein A agarose beads (Millipore) for $1 \mathrm{hr}$ at $4{ }^{\circ} \mathrm{C}$ under constant agitation to remove nonspecific binding. After removing the agarose beads, primary antibodies against human Pre6/PSMA7 (EPR5836, Abcam), a CP subunit, or Rpt1/PSMC2 (sc-166972, Santa Cruz), a RP subunit, were incubated with the supernatant containing modified Pre1 or Rpn11, respectively. Fresh protein A beads were subsequently added to the supernatant after $1 \mathrm{hr}$ and incubated overnight at $4{ }^{\circ} \mathrm{C}$. The beads were isolated from the supernatant the next day by centrifugation and washed three times. Both the supernatant and the beads were loaded onto 4-12\% NuPAGE (Invitrogen), transferred to PVDF membranes and detected by Western blotting using anti-Rpn11 (38-0200, ThermoFisher) or anti-Pre1 
(ab140426, Abcam). Wild-type HEK293A cells were used as controls and followed the same treatment.

\section{Cell imaging preparations}

Cells were plated on glass coverslips $(0.17 \mathrm{~mm}$, Thorlabs $)$ and grown at $37{ }^{\circ} \mathrm{C}$ in DMEM (Sigma) containing 10\% FBS and 1\% antibiotics one day before imaging. All glass coverslips were cleaned with Argon plasma for $1 \mathrm{hr}$ before incubation with cells. For the fixation procedure, cells were incubated with PBS buffer containing $4 \%$ paraformaldehyde and $0.2 \%$ glutaraldehyde for $10 \mathrm{~min}$ on the bench. Prior to imaging, cells were washed three times and imaged in warm OptiMEM (Sigma) filtered through $0.02 \mu \mathrm{m}$ pores. A metal chamber containing $1 \mathrm{ml}$ OptiMEM was used to secure the coverslip above the objective. All imaging was performed in temperature-controlled chambers. For microtubule or actin depolymerisation assays, cells we incubated with $5 \mu \mathrm{M}$ colcemid (Sigma) or latrunculin A (Anachem), prepared in DMSO or ethanol, respectively, resulting in a 1:200 dilution from the stock solution. After $20 \mathrm{~min}$ or $2 \mathrm{hrs}$ at $37{ }^{\circ} \mathrm{C}$, cells were taken out from the incubator and washed three times using OptiMEM before imaging as described above.

\section{TIRF and HILO instrument and imaging 2D}

Imaging was performed using a bespoke TIRF microscope. Diode lasers operating at $405 \mathrm{~nm}$ (Cobolt MLD), $488 \mathrm{~nm}$ (Topica) or $561 \mathrm{~nm}$ (Cobolt Jive 500) were directed into an oilimmersion TIRF objective (60× Apo N TIRF, NA 1.49, Olympus) mounted on an Eclipse Ti2 microscope (Nikon Corporation). The change from HILO to TIRF mode was achieved by altering the beam offset perpendicular to the optical axis resulting in total internal reflection/HILO imaging. Emitted fluorescence was collected by the same objective and separated from the returning TIR beam by a dichroic filter (Di01-R405/488/561/635-25×36; Semrock). Emission filters were applied for eGFP (FF01-496/LP-25, FF01-520/44-25) or mEos (BLP02-561R-25, FF01-607/36-25) imaging. Images were recorded on an EMCCD camera (Evolve 512Delta, Photometrics), by alternating between laser excitation sources (561

$\mathrm{nm}$ laser at $0.8 \mathrm{kWcm}^{-2}, 488 \mathrm{~nm}$ at $1.5 \mathrm{kWcm}^{-2}$ and $405 \mathrm{~nm}$ at $0.7 \mathrm{kWcm}^{-2}$, determined by measuring the power exiting the objective and the footprint of the beam in the imaging plane) using mechanical shutters (Prior Scientific) and an exposure of $50 \mathrm{~ms}$ (localisation). For 
single-molecule tracking, an exposure of $5 \mathrm{~ms}$ was used. A short pulse of $405 \mathrm{~nm}$ was used to photoconvert mEos, which was subsequently excited using the $561 \mathrm{~nm}$ laser. The pixel size $(107 \mathrm{~nm})$ was measured prior to recordings.

\section{fPALM image analysis}

The image analysis of the fPALM and ER respective density analysis was performed using FiJi and custom Matlab scripts. To generate masks for the ER, the cell and the nucleus, the image stacks of the bulk mEos intensity were averaged and background subtracted using FiJi rolling background subtraction (radius of 50 pixels). The masks for the nucleus were selected manually and the cell edges were detected using gradient-based thresholding, which were filled to create the cell mask. Localisations within the nucleus versus the outside of the nucleus where counted and related to their respective areas. For SFigure 3, the ER mask was created using intensity-based thresholding (70\% of maximum intensity) while the cytoplasm mask was defined as cell mask minus ER and nucleus mask. The localisation of the mEos signals was done after a rolling background subtraction (radius of 3 pixels) using the freely available localization software PeakFit (www.sussex.ac.uk/gdsc/intranet/microscopy/imagej/

$\underline{\text { smlm plugins) }}$. Only localisations with a precision smaller than $40 \mathrm{~nm}$, a minimum of 30 photons and a signal strength of 40 were taken into account.

\section{Single-molecule tracking}

Single-molecule images were analysed using a custom Matlab script ${ }^{35}$. A bandpass filter ( 1 to 5 pixels) was first applied, followed by identification of local maxima in raw images. Maxima were identified based on a signal-to-noise threshold, which was set to 4, and spots with a radius less than 8 pixels were then linked together to form tracks ${ }^{43}$. The tracking algorithm allowed molecules to move a maximum distance of 6 pixels per frame. Only tracks longer than 6 frames were used for analysis.

\section{Diffusion analysis by Jump distance}

Jump distance $(J D)$ analysis has been described before ${ }^{35,44}$ and was applied to tracks detected from each imaged cell to investigate heterogeneities in the diffusion coefficient distribution. 
Briefly, the probability distribution $P\left(r^{2}, \Delta t\right)$ of the squared distance, $\mathrm{r}^{2}$, traveled in one time step, $\Delta t$, was fitted using

$$
P\left(r^{2}, \Delta t\right)=\sum_{j=1}^{m} \frac{f_{i}}{4 D_{j} \Delta t} e^{-\frac{r^{2}}{4 D_{j} \Delta t}}
$$

where $f$ is the fraction corresponding to population $j$, and $m$ is the number of populations. $J D$ analysis was applied to tracks from each cell individually. $m$ was selected by evaluating the coefficient of determination, $R^{2}$, of the fit to a single population. $m=1$ for $R^{2}>0.9$ and $m=2$ for $R^{2}<=0.9\left(\right.$ detailed in $\left.^{35}\right)$.

\section{Double-helix Point Spread Function imaging in 3D}

Double-Helix Point Spread Function imaging was performed as previously described ${ }^{45}$. Briefly, DHPSF imaging was carried out on a bespoke microscope incorporating a NA 1.27 water immersion objective lens (CFI Plan Apo IR SR 60XWI, Nikon) mounted on a scanning piezo stage (P-726 PIFOC, PI) onto a conventional inverted microscope body (Eclipse Ti-U, Nikon). A 4f system of lenses with a $580 \mathrm{~nm}$ optimised double-helix phase mask (DoubleHelix, Boulder USA) placed in the Fourier-plane performed the DHPSF transformation and relayed the image onto an EMCCD camera (Evolve 512Delta, Photometrics). Collimated $561 \mathrm{~nm}$ (200 mW, Cobolt Jive 100) and $405 \mathrm{~nm}$ (120 mW, iBeam smart-405-s, TOPTICA) lasers were directed into the objective lens, resulting in a power density at the sample of $\sim 1 \mathrm{kWcm}^{-2}$ and $\sim 0.1 \mathrm{kWcm}^{-2}$, respectively. The fluorescence signal was separated from the laser excitation by a quad-band dichroic filter (Di01R405/488/561/635-25x36, Semrock). Additional isolation of the fluorescence signal was achieved by long-pass and band-pass filters placed directly before the detector (BLP02-561R25 \& FF01-580/14-25, Semrock). All DHPSF data was analysed by easy-DHPSF software ${ }^{46}$ and was rendered using $\mathrm{ViSP}^{47}$.

\section{Patch clamp and imaging}

Recording pipettes (4-6 M $\Omega$ ) were pulled from borosilicate glass, and were filled with an internal solution (135 $\mathrm{mM}$ potassium gluconate, $10 \mathrm{mM}$ HEPES, $10 \mathrm{mM}$ sodium phosphocreatine, $4 \mathrm{mM} \mathrm{KCl,} 4 \mathrm{mM} \mathrm{MgATP}, 0.3 \mathrm{mM} \mathrm{Na} 2 \mathrm{GTP}, \mathrm{pH} 7.2$ [adjusted with $\mathrm{KOH}$ ]) 
and osmolarity set to $291 \mathrm{mOsmol} \mathrm{l}^{-\mathrm{m}}$. Signals were acquired using an Axon Multiclamp 200B amplifier (Molecular Devices). Recordings were low-pass filtered at $2 \mathrm{kHz}$ and acquired at $5 \mathrm{kHz}$ using an NI $\mathrm{X}$ Series Multifunction DAQ (National Instrument) programmed by Axograph software. Membrane voltage was recorded in the current clamp mode. Series resistance was 10-25 Mso and experiments were terminated if this range was exceeded.

To investigate proteasomal responses to the membrane potential, the membrane potential of cells were manipulated in voltage clamp mode with a $30 \mathrm{~s}$ step (unless otherwise specified) of $-100 \mathrm{mV}$ or $+100 \mathrm{mV}$ alternatively. Current traces were filtered at $2 \mathrm{kHz}$ and digitally sampled at $20 \mathrm{kHz}$ using AxoGraph software. The bath level of the recording chamber was kept to a minimum to reduce pipette capacitance. Leak current was subtracted off-line using a template constructed from the currents induced by a $-10 \mathrm{mV}$ hyperpolarizing step.

White-light transmission and fluorescence images were acquired with a modified fluorescent microscope based on an inverted microscope, equipped with an infinity-corrected oil immersion objective (Olympus UPlanApo, 100×, NA 1.4), operating in TIRF imaging mode to reduce the excitation volume, and detected on a $512 \times 512$ pixel EMCCD (Evolve 512Delta, Photometrics)) at a rate of $50 \mathrm{~ms}$ per frame for proteasome imaging. The filters used were a dichroic mirror (Di01-R405/488/561/635-25x36, Semrock) and a 525/50 nm band pass filter (FF03-525/50-25; Semrock). Laser excitation was provided by a $488 \mathrm{~nm}$ solid-state laser (Spectra-Physics) at a power density of $\sim 0.7 \mathrm{kWcm}^{-2}$.

\section{Potential regulated imaging analysis}

Image Analysis was done using Fiji and custom-written Matlab code. Image stacks were bleach-corrected using the in-built exponential bleach correction function of Fiji (Kota Miura et al. (2014). ImageJ Plugin CorrectBleach V2.0.2. Zenodo. 10.5281/zenodo.30769) applied to the cell of interest. Subsequently, the stacks were 10-fold binned in time to generate frame rates of $500 \mathrm{~ms}$. For the image analysis time-traces from the cell of interest were low-pass filtered at a pass band frequency of $0.05 \mathrm{~Hz}$, a steepness of 0.85 and stop band attenuation of $30 \mathrm{~dB}$. The resulting traces were then normalised to their maximum intensities and analysed using the Matlab function findpeaks, to detect maxima and minima with a prominence of $3 \%$ and a minimum peak distance of 50 frames. The rate of intensity increase per cell was 
measured as intensity increase over the time between the first minimum to the closest maximum. If there was only one peak detected the rate is calculated as intensity increase over the time between the peak and the local maxima or minima. If there were no peaks detected, the rate is calculated as the rate of signal increase over the minimum to the maximum of the entire trace. Every cell was therefore assigned a rate of intensity increase in relation to the maximum intensity of that cell. 


\section{Figure Legends}

Figure 1. HILO imaging of proteasome distribution in HEK cells. The localisation of endogenous (a) Rpn11-mEos, a RP subunit, and (b) Pre1-mEos, a CP subunit, were determined in fixed HEK cells that transiently expressed eGFP-sec61, an ER marker (white). Fluorescence from mEos found in the area surrounded by the sec61-marker (i.e. in the nucleus) are coloured cyan, while signals not found in the nucleus (i.e. in the ER/cytoplasm) are in yellow. Scale bar represents $1 \mu \mathrm{m}$. (c) "Density" of Rpn11- or Pre1-mEos was calculated from the fraction of signals found in each region divided by fraction of total cell area covered by each region ( $\mathrm{n}=9$ and $\mathrm{n}=16$, respectively, see Materials and Methods). Box plots are used to represent mean value, 95\% confidence interval and range of each dataset. Statistical significance was calculated using student's t-test.

Figure 2. Single-proteasome tracking by TIRF imaging in live cells. (a) A fast- (red tracks) and a slow-diffusing (blue tracks) Rpn11-mEos signal (gold circles) are shown (pixel size $=$ $107 \mathrm{~nm}$, see also SVideo 1). (b, left) A representative jump distance analysis (frequency of displacement in cyan bars) of all Rpn11-mEos diffusion tracks detected within a typical cell. Diffusion coefficients for the fast- $\left(D_{\text {fast }}\right.$, red line), the slow population $\left(D_{\text {slow }}\right.$, blue line) and overall fitting (black line) are shown with the ratio of $D_{\text {fast }}$ to $D_{\text {slow }}$ for this particular cell. (right) Box plots showing the distribution of $D_{\text {fast }}$ (mean and standard deviation (SD) value $\left.3.7 \pm 1.0 \mu \mathrm{m}^{2} / \mathrm{s}\right), D_{\text {slow }}\left(0.8 \pm 0.2 \mu \mathrm{m}^{2} / \mathrm{s}\right)$ and their ratios $\left(D_{\text {fast }}\right.$ is $0.54 \pm 0.08$ by fractional representation) recorded from 14 cells. (c) Jump distance analysis to determine diffusion coefficients (mean values for $D_{\text {fast }}$ and $D_{\text {slow }}$ are $4.1 \pm 1.2 \mu \mathrm{m}^{2} / \mathrm{s}$ and $0.8 \pm 0.2 \mu \mathrm{m}^{2} / \mathrm{s}$, respectively, with $D_{\text {fast }} 0.49 \pm 0.09$ of total) of 16 Pre 1 -mEos cells as in $\mathbf{b}$.

Figure 3. Membrane potential modulates proteasome localisation. (a) Unpatched and patched cells are imaged in TIRF mode with snapshots shown from various time points (four panels of $t 1-t 4$ as in $\mathbf{b}$ below), where the normalised fluorescence intensity is coloured (see Materials and Methods for image processing and bleach correction). The position of the applied patch clamp is marked with an " $x$ " (red) on the cell in $t 1$. Regions of the patched cell used for intensity plots are marked in panel $t$. (b) Changes in normalised fluorescence signal over time are plotted for each cell, colour-coded as in a. Solid black lines represent signals after applying a filter in the frequency dimension to remove modulations smaller than the 
oscillation in potential. The clamped potentials applied are indicated on the top and oscillated between $+100 \mathrm{mV}$ (red) and $-100 \mathrm{mV}$ (blue) every $60 \mathrm{~s}$. (c-d) Voltage-clamp applied (30 s oscillation) on (c) a transgenic Rpn11-eGFP cell and (d) a HEK cell transiently expressing eGFP-USP21 and imaged as in a. Hyperpolarised (left) or depolarised (right) states of the same cell are shown. (e) Fluorescence intensity of the encircled cells in $\mathbf{c}$ and $\mathbf{d}$ traced over time and with respect to the clamped voltage indicated above the graph. (f) The rate of change was calculated from repeated measurements of normalised fluorescence intensities $(\mathrm{nFI})$ induced by oscillating the membrane potential in Pre1-eGFP (mean and SD $=0.037 \pm$ $0.023 \mathrm{nFI} / \mathrm{s}, \mathrm{n}=9)$, Rpn11-eGFP $(0.033 \pm 0.08 \mathrm{nFI} / \mathrm{s}, \mathrm{n}=6)$ or eGFP-USP21 (0.002 \pm 0.005 $\mathrm{nFI} / \mathrm{s}, \mathrm{n}=6$ ) cells. Scale bars represent $5 \mu \mathrm{m}$. All images are contrast-adjusted for optimal representation of the difference in intensity between hyper- and depolarised states.

Figure 4. Depolymerisation of microtubules and actin filaments affect potential-induced proteasome re-localisation. (a) Pre1-eGFP cells were treated with $5 \mu \mathrm{M}$ Colcemid or Latrunculin A (LatA) for $20 \mathrm{~min}$ at $37^{\circ} \mathrm{C}$ and washed with cell media before mounted for TIRF imaging. Fluorescence images shown represent hyperpolarised (top) or depolarised (bottom) state (oscillation time $30 \mathrm{~s}$ ). (b) Pre1-eGFP cells treated with DMSO or ethanol $(\mathrm{EtOH})$ vehicle controls are presented as in a. (c) Fluorescence intensity traces of the cells in $\mathbf{a}$ and $\mathbf{b}$ are plotted over time and the applied potential at each time indicated. (d) Repeated measurements of patch clamp applied on Pre1-eGFP cells treated with (from left) DMSO (mean rate with $\mathrm{SD}=0.031 \pm 0.009 \mathrm{nFI} / \mathrm{s}, \mathrm{n}=4), \mathrm{EtOH}(0.032 \pm 0.004 \mathrm{nFI} / \mathrm{s}, \mathrm{n}=4)$, Colcemid $(0.0001 \pm 0.0003 \mathrm{nFI} / \mathrm{s}, \mathrm{n}=4)$, LatA $(-0.004 \pm 0.006 \mathrm{nFI} / \mathrm{s}, \mathrm{n}=5)$, and Rpn11eGFP cells treated with Colcemid $(-0.0002 \pm 0.0002 \mathrm{nFI} / \mathrm{s}, \mathrm{n}=4)$ and LatA $(0.006 \pm 0.009$ $\mathrm{nFI} / \mathrm{s}, \mathrm{n}=8$ ) performed as in $\mathbf{a}$ and $\mathbf{b}$. All images are contrast-adjusted for optimal representation of the difference in intensity between hyper- and depolarised states.

Figure 5. Single-proteasome tracking in cells after prolonged drug treatment. (a) The range of diffusion coefficients (from left) for untreated Rpn11-eGFP cells (as in Figure 2) or incubated with LatA (mean $D_{\text {fast }}$ with SD $=4.2 \pm 0.9 \mu \mathrm{m}^{2} / \mathrm{s}$ and $D_{\text {slow }}=0.8 \pm 0.2 \mu \mathrm{m}^{2} / \mathrm{s}, \mathrm{n}=7$ cells) or Colcemid $\left(D_{\text {fast }} 4.0 \pm 1.1 \mu \mathrm{m}^{2} / \mathrm{s}\right.$ and $\left.D_{\text {slow }} 0.9 \pm 0.2 \mu \mathrm{m}^{2} / \mathrm{s}, \mathrm{n}=8\right)$ for $2 \mathrm{hrs}$ at $37{ }^{\circ} \mathrm{C}$. The average value of $D_{\text {fast }}$ did not change either after depolymerising the cytoskeleton (fraction of $D_{\text {fast }} 0.48 \pm 0.05$ and $0.46 \pm 0.08$ with LatA and Colcemid, respectively). (b) The 
same observations are made for Pre1-eGFP cells with either depolymerised mictotubules

$\left(D_{\text {fast }} 3.8 \pm 1.3 \mu \mathrm{m}^{2} / \mathrm{s}\right.$ and $\left.D_{\text {slow }} 0.7 \pm 0.2 \mu \mathrm{m}^{2} / \mathrm{s}, \mathrm{n}=9\right)$ or actin filaments $\left(D_{\text {fast }} 4.6 \pm 1.3 \mu \mathrm{m}^{2} / \mathrm{s}\right.$ and $D_{\text {slow }} 0.8 \pm 0.2 \mu \mathrm{m}^{2} / \mathrm{s}, \mathrm{n}=9$ ) as presented in a. Fraction of $D_{\text {fast }}$ was $0.46 \pm 0.08$ and 0.48 \pm 0.09 after treatment with LatA and Colcemid, respectively. 


\section{Supplementary Figures}

SFigure 1. Co-immunoprecipitation of endogenously tagged Pre1 or Rpn11 subunits with fluorescent proteins (FPs). (a) Endogenous Pre1 proteins were pulled down with an anti-Pre6 antibody and detected by Western blotting against Pre1. The proteasomal proteins were trapped on the agarose beads (beads) while the flow-through (f/t) did not contain Pre1. From left: HEK control cells, Pre1-eGFP cells and Pre1-mEos. No interactions were detected between the beads and Pre1 without the antibody. (b) Endogenous Rpn11 proteins were pulled down with an anti-Rpt1 antibody, followed by Western blotting against Rpn11. Nonspecific bands detected by this antibody are marked with*. Numbers to the left represent molecular weight markers.

SFigure 2. Localisation precision of individual mEos particles detected in Figure 1. The Localisation precision of Pre1-mEos $(n=39458,20$ cells imaged) and Rpn11-mEos $(n=5027$, 10 cells imaged) was determined using the freely available localisation software PeakFit (see Materials and Methods).

SFigure 3. No significant colocalisation of proteasomal particles with the ER. Cells expressing endogenous (a) Rpn11-mEos or (b) Pre1-mEos from Figure 1 colour-coded when colocalised with the nucleus (blue), the ER (red) or the cytosol (green). (c) Calculated 'density' in 2D of the fraction of proteasomal particles found in each region as in Figure 1 (see Materials and Methods for full description).

SFigure 4. Distribution of Pre1-mEos and Rpn11-mEos particles by DHPSF imaging in space. DHPSF imaging of proteasomes shows the 3D distribution in HEK cells with a localisation precision of $\sim 25 \mathrm{~nm}$ laterally and $\sim 50 \mathrm{~nm}$ axially. (a) Pre1-mEos was imaged through a $\sim 4 \mu \mathrm{m}$ thick volume towards the apical surface of HEK cells. After spatial (200 nm) and temporal (1 s) filtering for repeat localisation of the same fluorophore, 15,878 localisations were recorded. (b) Rpn11-mEos was imaged through a $\sim 4 \mu$ thick volume towards the apical surface of HEK cells and 17,275 localisation after spatial (200 nm) and temporal (1 s) filtering for repeat localisation of the same fluorophore. Localisations are 
rendered with $100 \mathrm{~nm}$ FWHM for visibility. Scale bars for (a-c) are $10 \mu \mathrm{m}$. All localisations are coloured axially from $0 \mu \mathrm{m}$ (blue) to $4 \mu \mathrm{m}$ (red).

SFigure 5. Representative JD analyses of single-particle tracking of (a) Rpn11-mEOS and Pre1-mEos cells and (b) Rpn11-mEos cell treated with $50 \mathrm{mM} \mathrm{CaCl}_{2}$ and measured immediately afterwards. (c) Repeated measurements of untreated and $\mathrm{CaCl}_{2}$-treated Rpn11mEos (top, $\mathrm{n}_{\text {untreated }}=10$ and $\mathrm{n}_{\text {treated }}=13$ cells, $D_{\text {fast }}$ reduced from $4.1 \pm 1.1$ to $2.3 \pm 0.8 \mu \mathrm{m}^{2} / \mathrm{s}$ and $D_{\text {slow }}$ from $0.9 \pm 0.3$ to $0.6 \pm 0.2 \mu \mathrm{m}^{2} / \mathrm{s}$; mean and SD) and Pre1-mEos (bottom, $\mathrm{n}_{\text {untreated }}=$ 8 and $\mathrm{n}_{\text {treated }}=13, D_{\text {fast }}$ reduced from $\sim 3.05 \pm 0.8$ to $\sim 2.1 \pm 0.9 \mu \mathrm{m}^{2} / \mathrm{s}$ and $D_{\text {slow }}$ from $0.7 \pm$ 0.2 to $0.5 \pm 0.1 \mu \mathrm{m}^{2} / \mathrm{s}$ ) cells and the relative abundance of $D_{\text {fast }}$ (from $0.52 \pm 0.1$ to $0.40 \pm 0.1$ for Rpn 11 -mEos and from $0.51 \pm 0.1$ to $0.42 \pm 0.1$ for Pre 1 -mEos cells) in TIRF mode. Data presented as in Figure 2.

SFigure 6. Single-particle tracking of (a) Pre1-eGFP and (b) Rpn11-eGFP cells in HILO mode ( $n=13$ and $n=16$ cells, respectively) gave similar diffusion coefficients as in Figure 2, suggesting that proteasomal particles diffuse with similar behaviour across the cell. Due to increased photo-bleaching in HILO mode, tracks from multiple cells were combined for jump distance analysis.

SFigure 7. Transient expression of eGFP-USP21 in HEK cells $(n=8$ cells) and used as a control protein of similar molecular weight as Rpn11 but does not form part of proteasomal particles. Data presented as in Figure 2.

SFigure 8. Current(I)-potential(V) relationship from patch clamped HEK cells imaged by TIRF. (a) A typical set of voltage responses to current injections in a Pre1-eGFP cell and (b) corresponding IV curve of a recorded cell. (c) Voltage control $(+100 \mathrm{mV}$ or $-100 \mathrm{mV})$ of recorded Pre1-eGFP cells with 30 s step plotted here against the current response to the voltage control. (d) Averaged current response range of HEK cells at holding potential $+100 \mathrm{mV}$ or $-100 \mathrm{mV}(\mathrm{n}=14$ cells $)$. 
SFigure 9. Voltage clamped Pre1-eGFP cell as in Figure 3 and (a) illuminated with white light (top) and with HILO imaging (bottom). The position of the patch is marked with an " $x$ " and remained immobile throughout the measurement. (b) Fluorescence intensity plots over time as detected in a peripheral region (P) and an interior region (I) of the patched cell or a control region $(\mathrm{C})$ of an unpatched cell. The applied potential oscillated between $+100 \mathrm{mV}$ and $-100 \mathrm{mV}$ as indicated on top of the graph. Scale bar represents $5 \mu \mathrm{m}$. Typical results presented here of triplicate repeats. Fluorescence is contrast adjusted to enhance difference in intensity between hyper- and depolarised states.

SVideo 1. TIRF imaging of two Rpn11-eGFP molecules with distinct movement pattern, as shown in Figure 2a. Scale bar indicates $0.5 \mu \mathrm{m}$.

SVideo 2. TIRF imaging of Rpn11-eGFP (left) and Pre1-eGFP (right) diffusion in live cells recorded at $5 \mathrm{~ms}$ per frame. Scale bars indicate $2 \mu \mathrm{m}$.

SVideo 3. HILO imaging (pixels zoomed $5 \times$ ) of a Pre1-eGFP cell before (left) or immediately after (right) increasing the concentration of $\mathrm{CaCl}_{2}$ to $50 \mathrm{mM}$ recorded at $50 \mathrm{~ms}$ per frame. Scale bar represents $2 \mu \mathrm{m}$.

SVideo 4. TIRF imaging in a live cell transiently expressing eGFP-USP21 recorded at $5 \mathrm{~ms}$ per frame. Scale bar indicates $2 \mu \mathrm{m}$.

SVideo 5. Patched Pre1-eGFP cell (left) and control cells (right, top and bottom) imaged in TIRF mode undergoing oscillation between hyperpolarisation $(-100 \mathrm{mV}$, blue) and depolarisation $(+100 \mathrm{mV}$, red) as in Figure 3a. Scale bar indicates $5 \mu \mathrm{m}$. The video was contrast-adjusted for optimal representation of the difference in intensity between hyper- and depolarised states.

SVideo 6. Patched Rpn11-eGFP cell imaged in TIRF mode undergoing oscillation between hyperpolarisation $(-100 \mathrm{mV}$, blue) and depolarisation $(+100 \mathrm{mV}$, red) as in Figure 3c. Scale bar indicates $5 \mu \mathrm{m}$. The video was contrast-adjusted for optimal representation of the difference in intensity between hyper- and depolarised states.

Svideo 7. Patched cell expressing eGFP-USP21 from a plasmid vector and imaged in TIRF mode undergoing oscillation between hyperpolarisation $(-100 \mathrm{mV}$, blue) and depolarisation 
$(+100 \mathrm{mV}$, red) as in Figure 3d. Scale bar indicates $5 \mu \mathrm{m}$. The video was contrast-adjusted for optimal representation of the difference in intensity between hyper- and depolarised states.

SVideo 8. Patched Pre1-eGFP cells treated with Colcemid (top left), Latrunculin A (top right), DMSO (bottom left, reduced to $62.5 \%$ of original size) or ethanol (bottom right) imaged in TIRF mode undergoing oscillation between hyperpolarisation $(-100 \mathrm{mV}$, blue $)$ and depolarisation $(+100 \mathrm{mV}$, red) as in Figure 4. Scale bars indicate $5 \mu \mathrm{m}$. All videos were contrast-adjusted for optimal representation of the difference in intensity between hyper- and depolarised states. 
$\underline{\text { References }}$

1. Varshavsky, A. The Ubiquitin System, Autophagy, and Regulated Protein Degradation. Annu. Rev. Biochem. 86, 123-128 (2017).

2. Dikic, I. Proteasomal and Autophagic Degradation Systems. Annu. Rev. Biochem. 86, 193-224 (2017).

3. Collins, G. A. \& Goldberg, A. L. The Logic of the 26S Proteasome. Cell 169, 792-806 (2017).

4. Hendil, K. B., Hartmann-Petersen, R. \& Tanaka, K. 26 S proteasomes function as stable entities. Journal of Molecular Biology 315, 627-636 (2002).

5. Schweitzer, A. et al. Structure of the human 26 S proteasome at a resolution of 3.9 A. Proceedings of the National Academy of Sciences 113, 7816-7821 (2016).

6. Huang, X., Luan, B., Wu, J. \& Shi, Y. An atomic structure of the human $26 \mathrm{~S}$ proteasome. Nature Structural \& Molecular Biology (2016). doi:10.1038/nsmb.3273

7. Lu, Y. et al. Conformational Landscape of the p28-Bound Human Proteasome Regulatory Particle. Molecular Cell 67, 322-333.e6 (2017).

8. Chen, S. et al. Structural basis for dynamic regulation of the human $26 \mathrm{~S}$ proteasome. Proc. Natl. Acad. Sci. U.S.A. 113, 12991-12996 (2016).

9. Bhattacharyya, S., Yu, H., Mim, C. \& Matouschek, A. Regulated protein turnover: snapshots of the proteasome in action. Nat Rev Mol Bio 15, 122-133 (2014).

10. Lafarga, M. et al. Clastosome: a subtype of nuclear body enriched in 19S and $20 \mathrm{~S}$ proteasomes, ubiquitin, and protein substrates of proteasome. Mol. Biol. Cell 13, 2771-2782 (2002).

11. Laporte, D., Salin, B., Daignan-Fornier, B. \& Sagot, I. Reversible cytoplasmic localization of the proteasome in quiescent yeast cells. The Journal of Cell Biology 181, 737-745 (2008).

12. Peters, L. Z., Hazan, R., Breker, M., Schuldiner, M. \& Ben-Aroya, S. Formation and dissociation of proteasome storage granules are regulated by cytosolic $\mathrm{pH}$. The Journal of Cell Biology 201, 663-671 (2013).

13. Reits, E. et al. Peptide diffusion, protection, and degradation in nuclear and cytoplasmic compartments before antigen presentation by MHC class I. Immunity 18, 97-108 (2003).

14. Pack, C.-G. et al. Quantitative live-cell imaging reveals spatio-temporal dynamics and cytoplasmic assembly of the $26 \mathrm{~S}$ proteasome. Nat Commun $\mathbf{5}$, 3396 (2014).

15. Scharf, A., Rockel, T. D. \& Mikecz, von, A. Localization of proteasomes and proteasomal proteolysis in the mammalian interphase cell nucleus by systematic application of immunocytochemistry. Histochem. Cell Biol. 127, 591-601 (2007).

16. Enenkel, C. Proteasome dynamics. Biochim. Biophys. Acta 1843, 39-46 (2014).

17. Chowdhury, M. \& Enenkel, C. Intracellular Dynamics of the UbiquitinProteasome-System. F1000Res 4, 367 (2015).

18. Asano, S. et al. Proteasomes. A molecular census of $26 \mathrm{~S}$ proteasomes in intact neurons. Science 347, 439-442 (2015).

19. Enenkel, C., Lehmann, A. \& Kloetzel, P.-M. Subcellular distribution of proteasomes implicates a major location of protein degradation in the nuclear envelope-ER network in yeast. The EMBO Journal 17, 6144-6154 (1998).

20. Brooks, P. et al. Subcellular localization of proteasomes and their regulatory complexes in mammalian cells. Biochem. J. 346 Pt 1, 155-161 (2000). 
21. Russell, S. J. Subcellular Localization, Stoichiometry, and Protein Levels of 26 S Proteasome Subunits in Yeast. Journal of Biological Chemistry 274, 2194321952 (1999).

22. Albert, S. et al. Proteasomes tether to two distinct sites at the nuclear pore complex. Proceedings of the National Academy of Sciences 114, 13726-13731 (2017).

23. Weberruss, M. H. et al. Blm10 facilitates nuclear import of proteasome core particles. The EMBO Journal 32, 2697-2707 (2013).

24. $\mathrm{Gu}, \mathrm{Z}$. C. et al. Ubiquitin orchestrates proteasome dynamics between proliferation and quiescence in yeast. Mol. Biol. Cell 28, 2479-2491 (2017).

25. Bingol, B. \& Schuman, E. M. Activity-dependent dynamics and sequestration of proteasomes in dendritic spines. Nature 441, 1144-1148 (2006).

26. Ramachandran, K. V. \& Margolis, S. S. A mammalian nervous-system-specific plasma membrane proteasome complex that modulates neuronal function. Nature Structural \& Molecular Biology 24, 419-430 (2017).

27. Waite, K. A., De-La Mota-Peynado, A., Vontz, G. \& Roelofs, J. Starvation Induces Proteasome Autophagy with Different Pathways for Core and Regulatory Particles. J. Biol. Chem. 291, 3239-3253 (2016).

28. Wójcik, C. \& Demartino, G. N. Intracellular localization of proteasomes. The International Journal of Biochemistry \& Cell Biology 35, 579-589 (2003).

29. BROOKS, P., Murray, R. Z., MASON, G. G. F., Hendil, K. B. \& RIVETT, A. J. Association of immunoproteasomes with the endoplasmic reticulum. Biochem. J. 352, 611-615 (2000).

30. Meyer, H., Bug, M. \& Bremer, S. Emerging functions of the VCP/p97 AAAATPase in the ubiquitin system. Nat Cell Biol 14, 117-123 (2012).

31. Berner, N., Reutter, K.-R. \& Wolf, D. H. Protein Quality Control of the Endoplasmic Reticulum and Ubiquitin-Proteasome-Triggered Degradation of Aberrant Proteins: Yeast Pioneers the Path. Annu. Rev. Biochem. 87, 751-782 (2018).

32. Shibata, Y. et al. Mechanisms determining the morphology of the peripheral ER. Cell 143, 774-788 (2010).

33. Tokunaga, M., Imamoto, N. \& Sakata-Sogawa, K. Highly inclined thin illumination enables clear single-molecule imaging in cells. Nature Methods 5, 159-161 (2008).

34. Dino Rockel, T. \& Mikecz, von, A. Proteasome-dependent processing of nuclear proteins is correlated with their subnuclear localization. JOURNAL OF STRUCTURAL BIOLOGY 140, 189-199 (2002).

35. Weimann, L. et al. A quantitative comparison of single-dye tracking analysis tools using Monte Carlo simulations. PLoS ONE 8, e64287 (2013).

36. UrbE, S. et al. Systematic survey of deubiquitinase localization identifies USP21 as a regulator of centrosome- and microtubule-associated functions. Mol. Biol. Cell 23, 1095-1103 (2012).

37. Park, J. et al. Screening Fluorescent Voltage Indicators with Spontaneously Spiking HEK Cells. PLoS ONE 8, e85221-10 (2013).

38. Hsu, K., Han, J., Shinlapawittayatorn, K., Deschenes, I. \& Marbán, E. Membrane Potential Depolarization as a Triggering Mechanism for Vpu-Mediated HIV-1 Release. Biophysj 99, 1718-1725 (2010).

39. Wang, X. \& Huang, L. Identifying dynamic interactors of protein complexes by quantitative mass spectrometry. Mol. Cell Proteomics 7, 46-57 (2008).

40. Chang, F. \& Minc, N. Electrochemical control of cell and tissue polarity. Annu. 
Rev. Cell Dev. Biol. 30, 317-336 (2014).

41. Urrego, D., Tomczak, A. P., Zahed, F., Stühmer, W. \& Pardo, L. A. Potassium channels in cell cycle and cell proliferation. Philos. Trans. R. Soc. Lond., B, Biol. Sci. 369, 20130094-20130094 (2014).

42. Guo, X. et al. Site-specific proteasome phosphorylation controls cell proliferation and tumorigenesis. Nat Cell Biol 18, 202-212 (2015).

43. Crocker, J. C., science, D. G. J. O. C. A. I.1996. Methods of digital video microscopy for colloidal studies. JOURNAL OF COLLOID AND INTERFACE SCIENCE 298-310 (1996). doi:10.1006/jcis.1996.0217

44. Ponjavic, A. et al. Single-Molecule Light-Sheet Imaging of Suspended T Cells. Biophysical Journal 114, 2200-2211 (2018).

45. Carr, A. R. et al. Three-Dimensional Super-Resolution in Eukaryotic Cells Using the Double-Helix Point Spread Function. Biophysical Journal 112, 1444-1454 (2017).

46. Lew, M. D., Diezmann, von, A. R. S. \& Moerner, W. E. Easy-DHPSF opensource software for three-dimensional localization of single molecules with precision beyond the optical diffraction limit. Protoc exch 2013, (2013).

47. Beheiry, El, M. \& Dahan, M. ViSP: representing single-particle localizations in three dimensions. Nature Methods 10, 689-690 (2013). 


\section{Figure 1}

bioRxiv preprint doi: https://doi.org/10.1101/487702; this version posted December 6, 2018. The copyright holder for this preprint (which was not certified by peer review) is the author/funder. All rights reserved. No reuse allowed without permission.

\section{a HILO imaging of Rpn11-mEos}

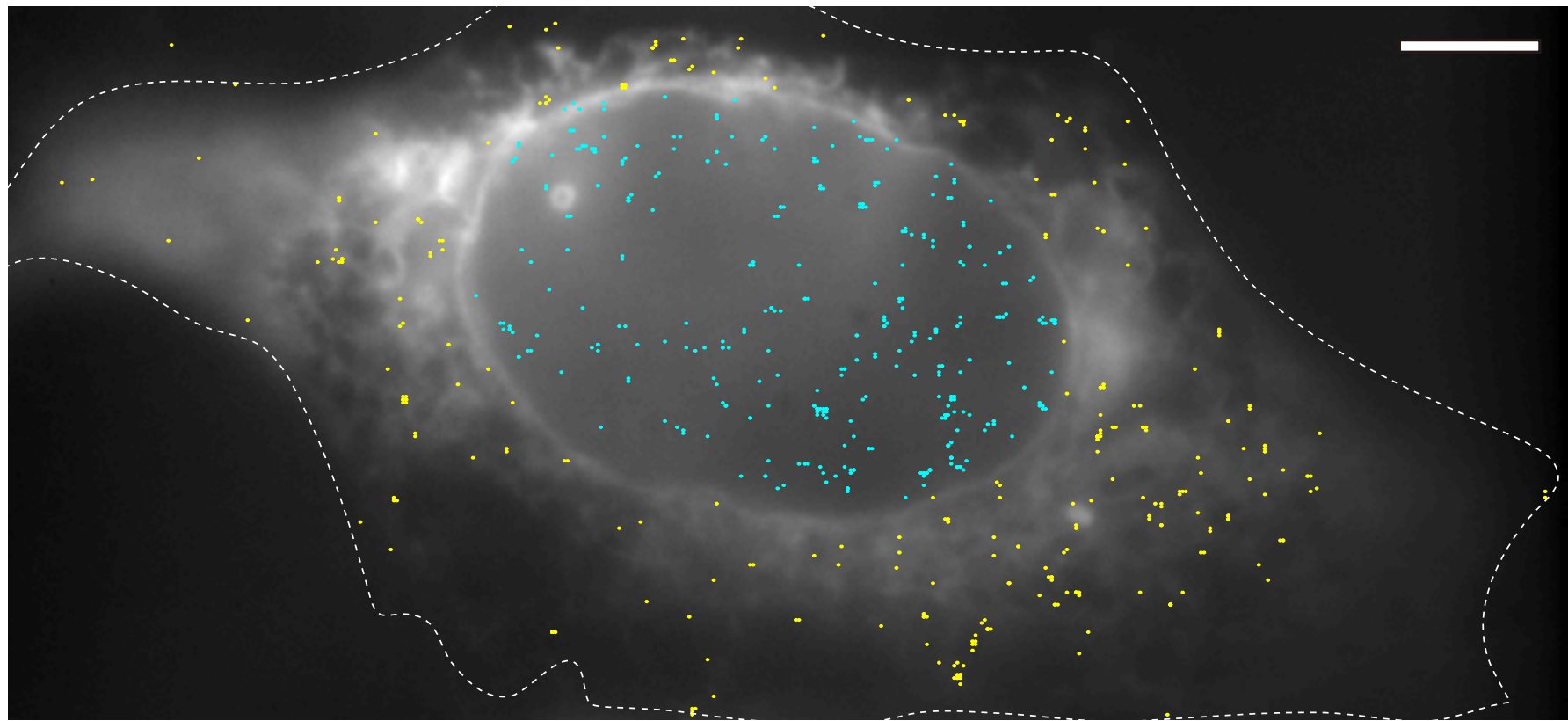

\section{HILO imaging of Pre1-mEos}

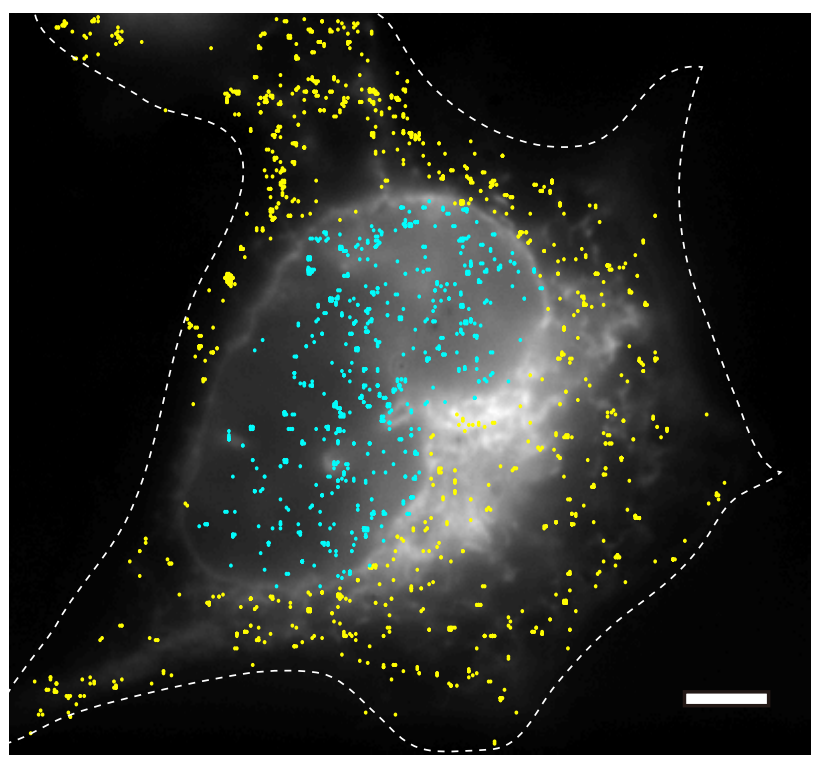

\section{Density of proteasome particles}

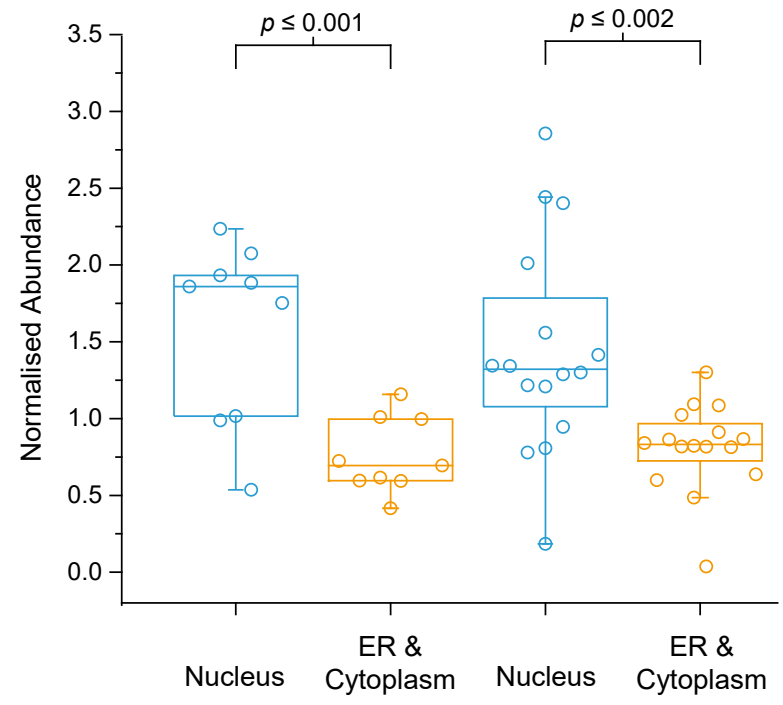

Rpn11-mEos Pre1-mEos 


\section{Figure 2}

S Single-molecule TIRF imaging of Rpn11-eGFP
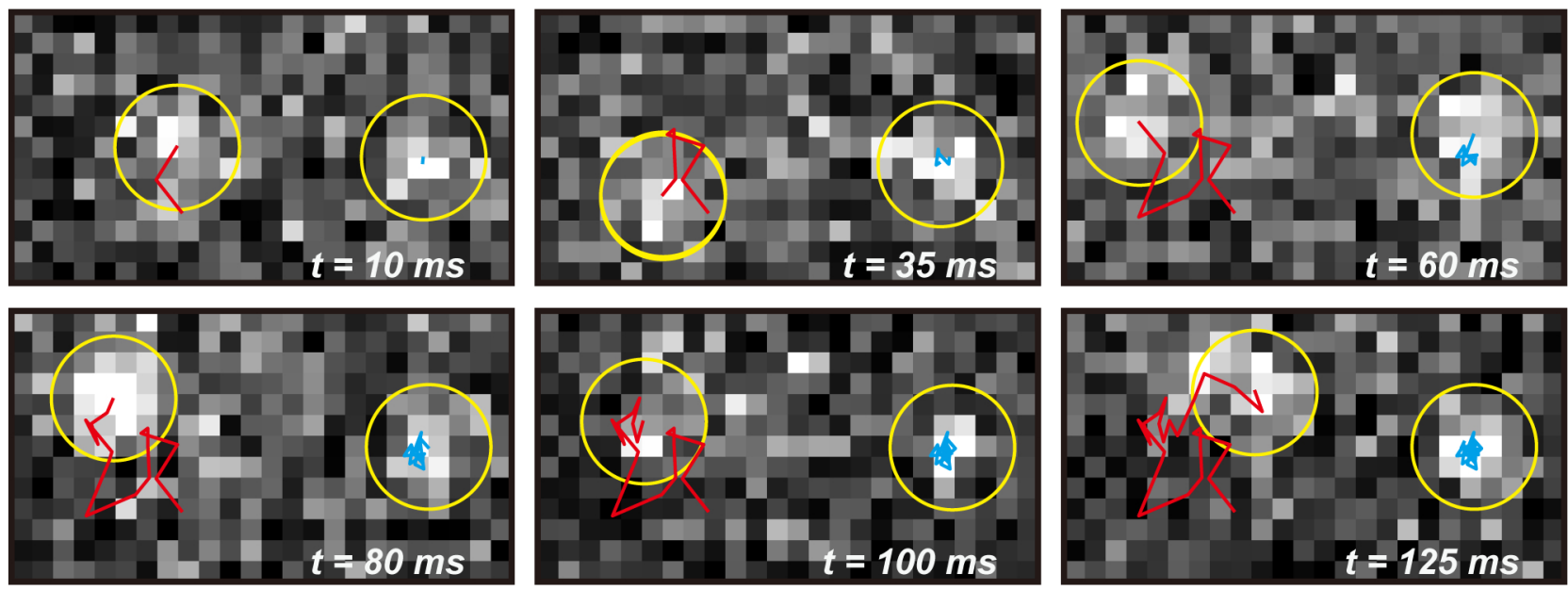

b

TIRF imaging of Rpn11-eGFP diffusion
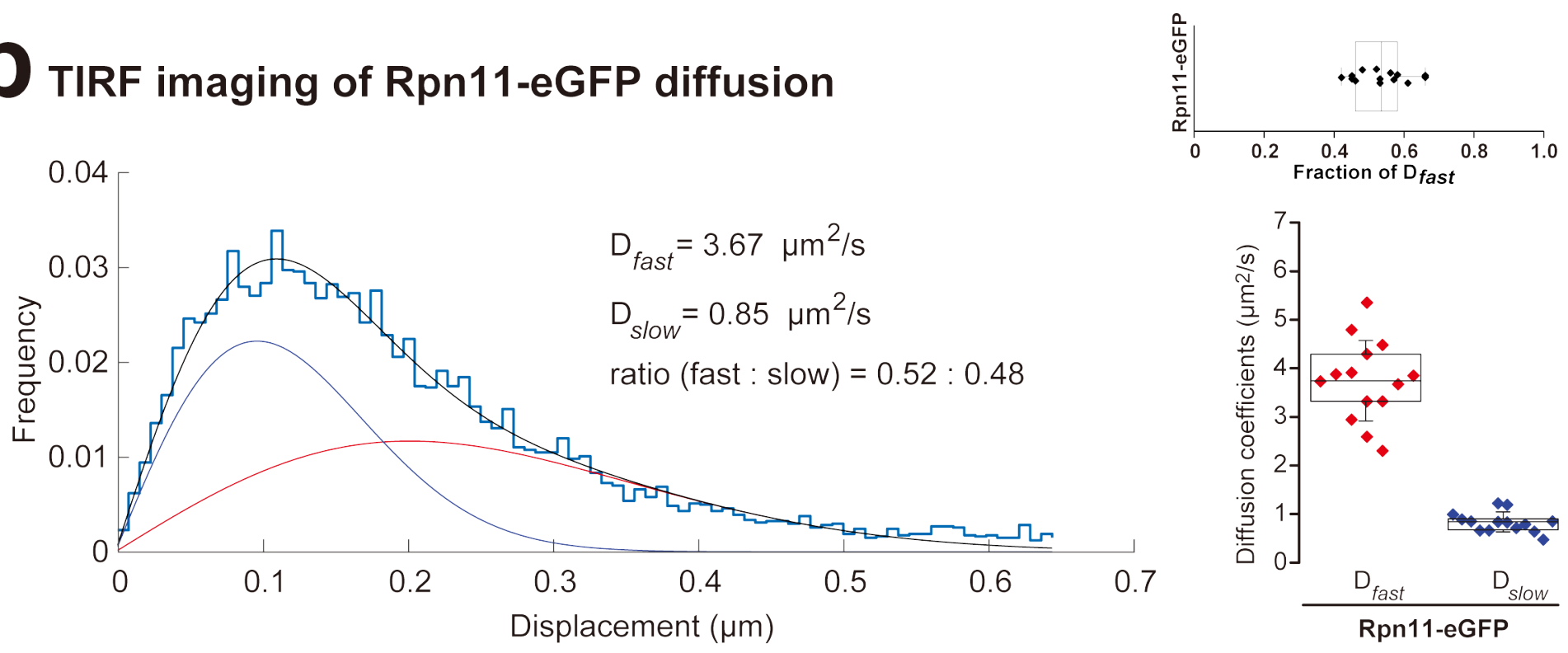

\section{C}

\section{TIRF imaging of Pre1-eGFP diffusion}
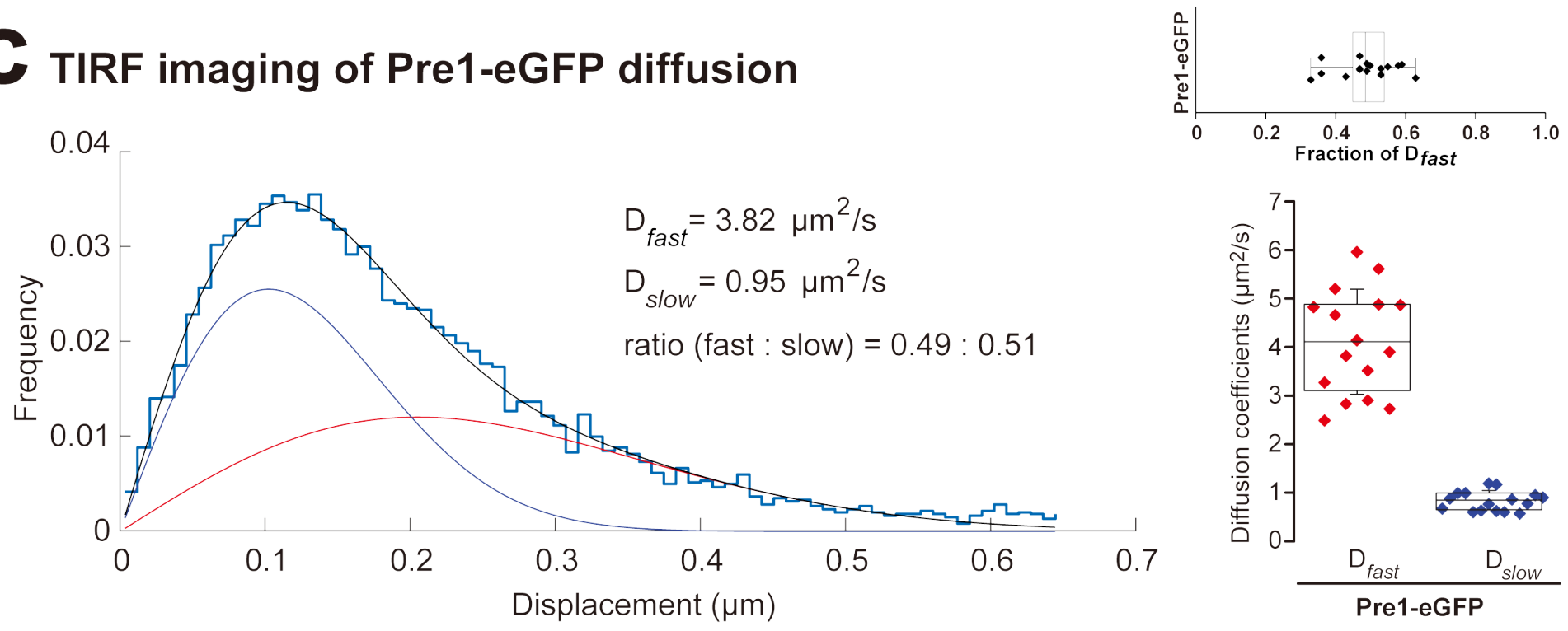


\section{Figure 3}

\section{a TIRF imaging of Pre1-eGFP with patch-clamp}
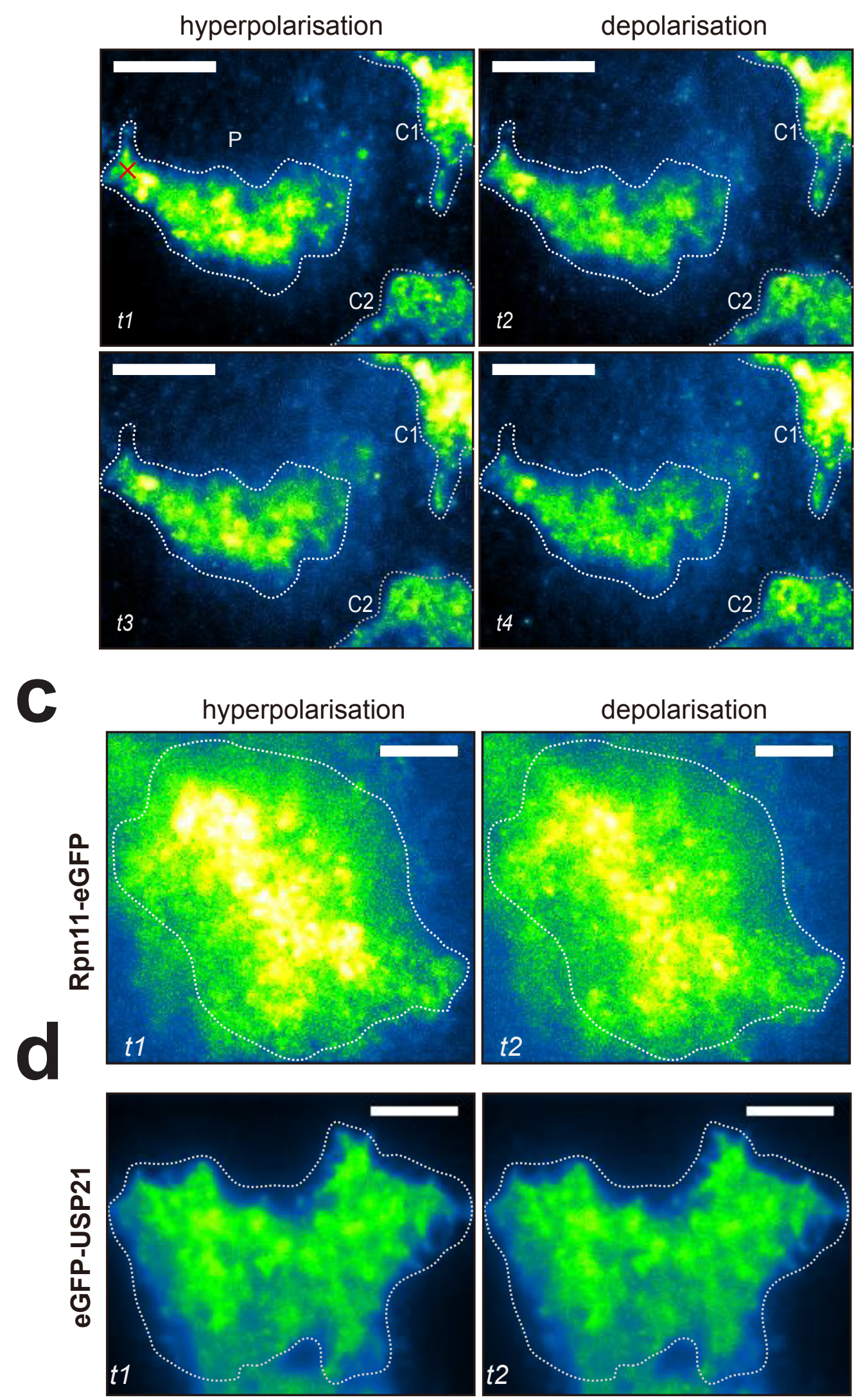

b

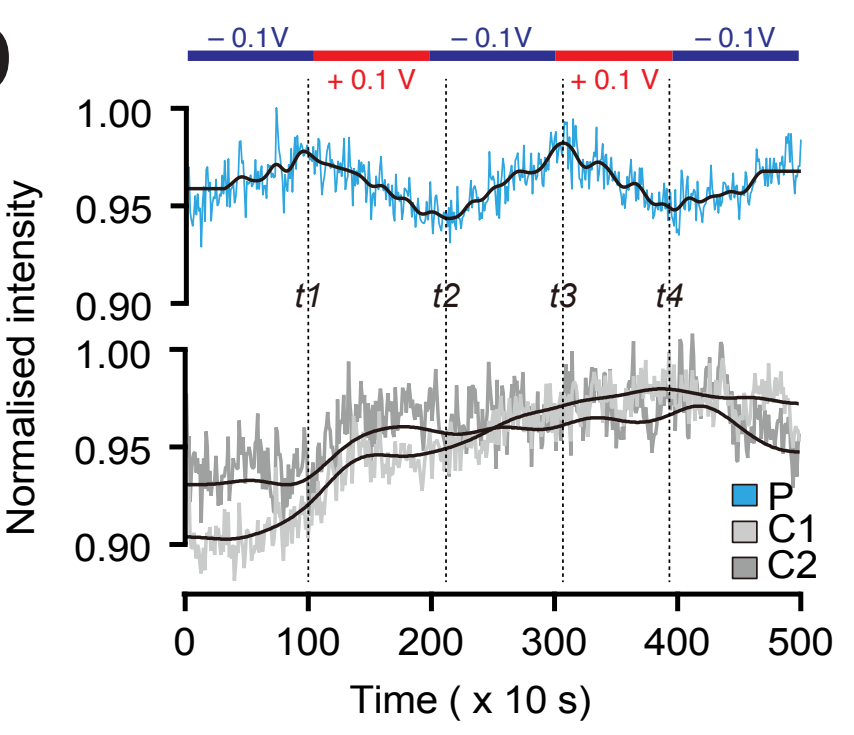

e

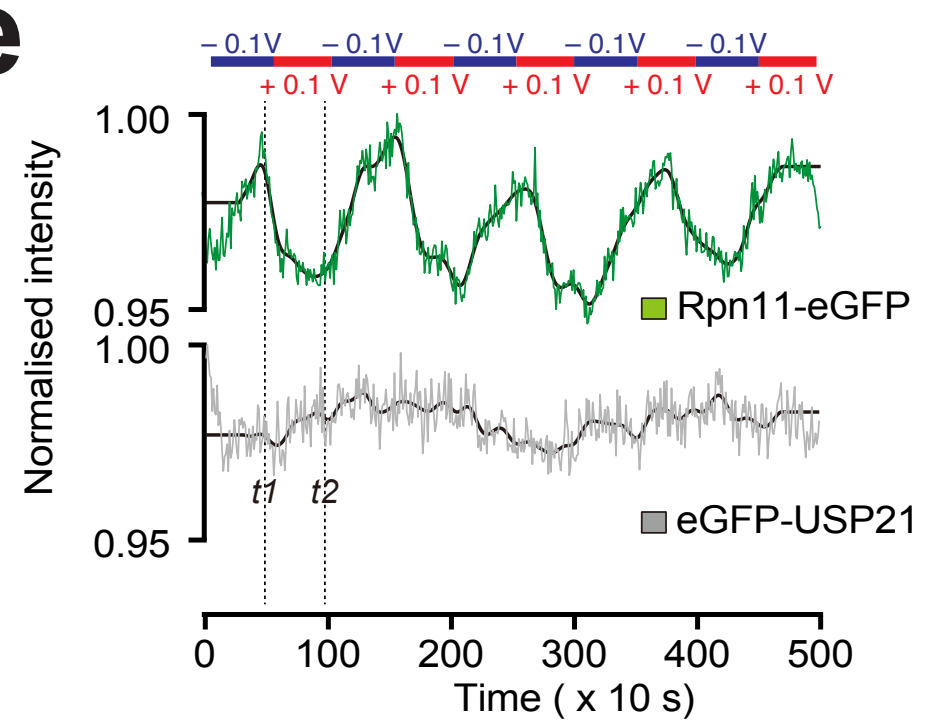

$f$

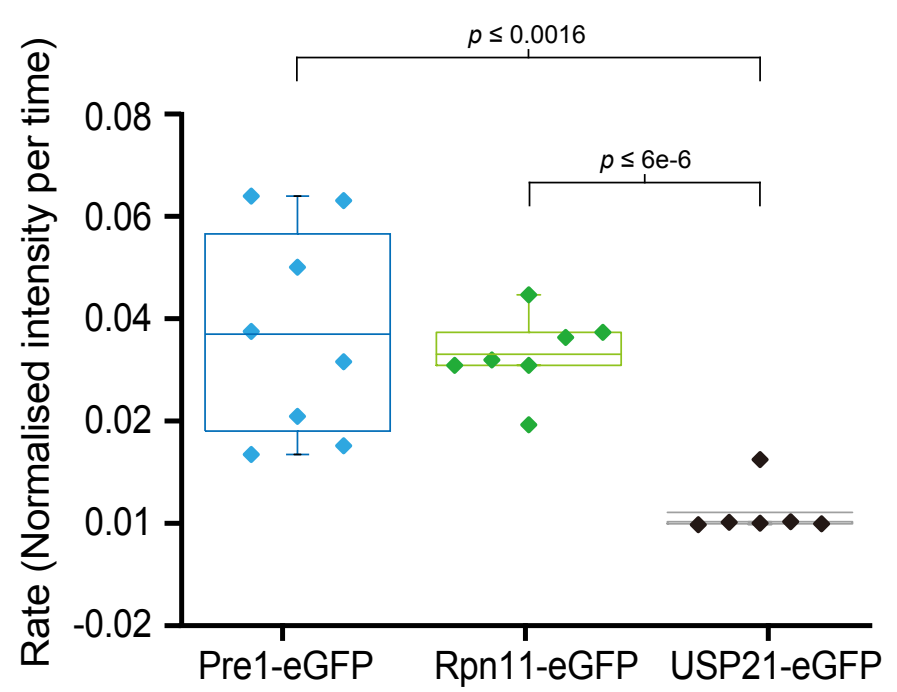


Figure 4 .

a Pre1-eGFP + Colcemid
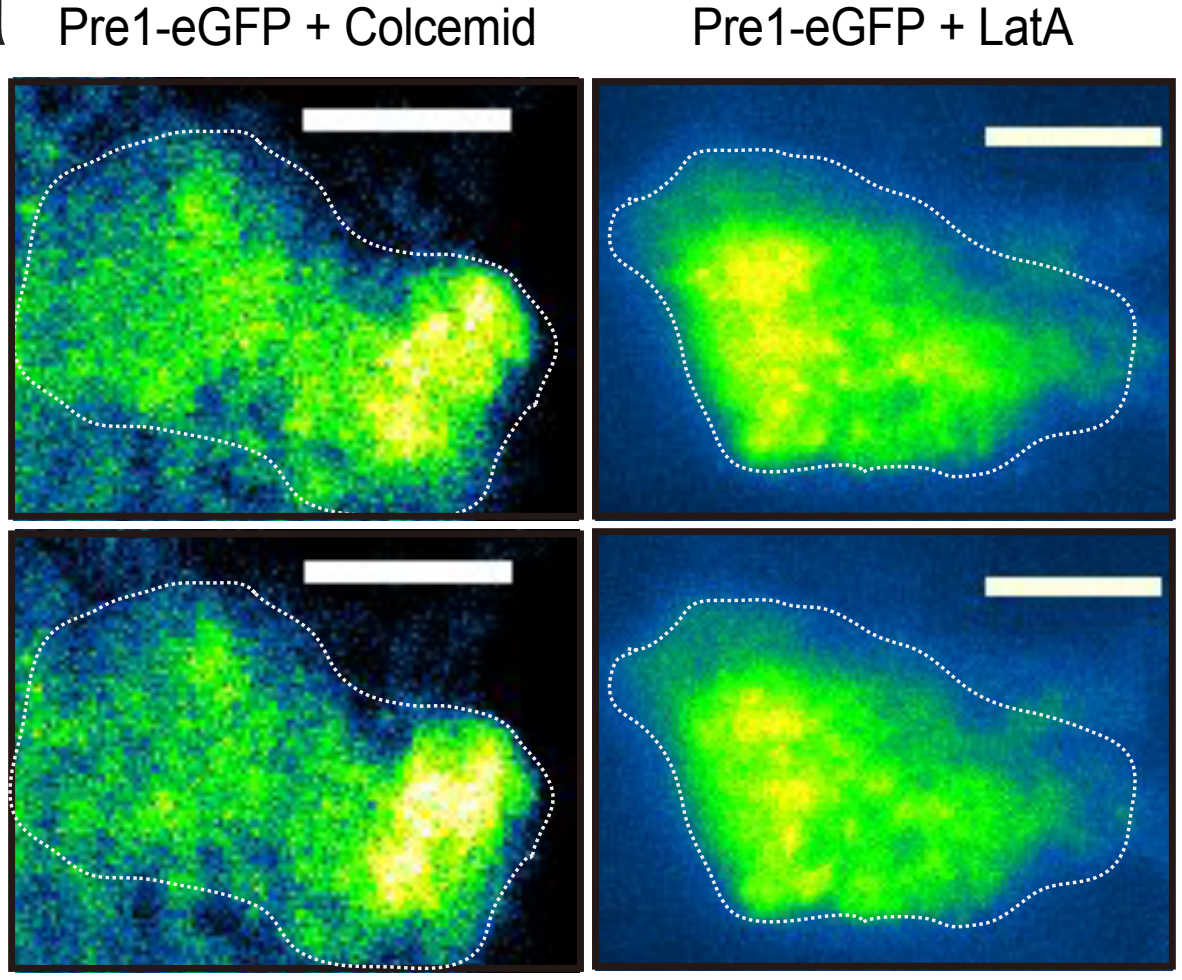

b

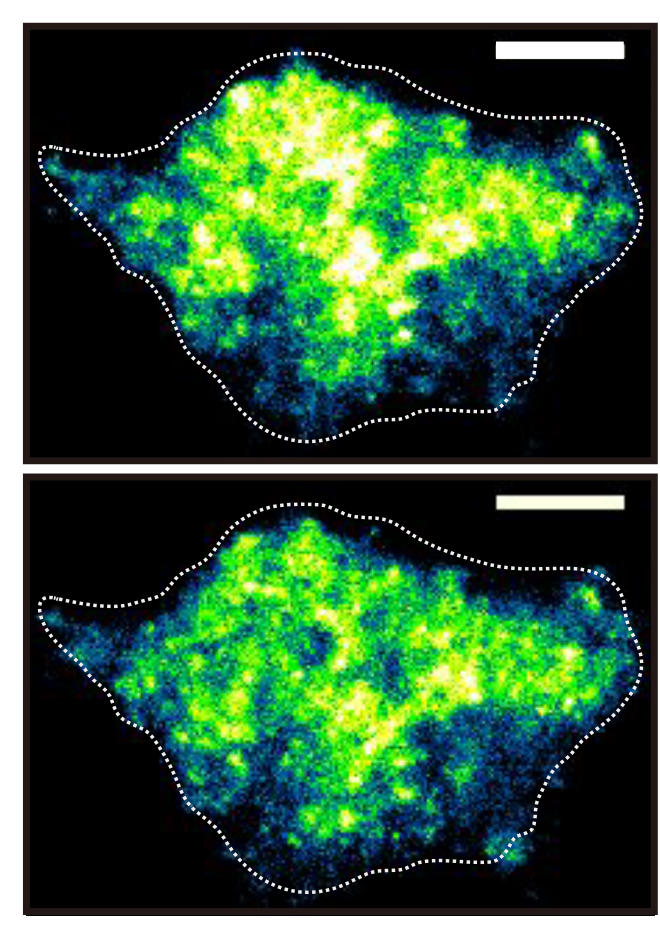

Pre1-eGFP + EtOH

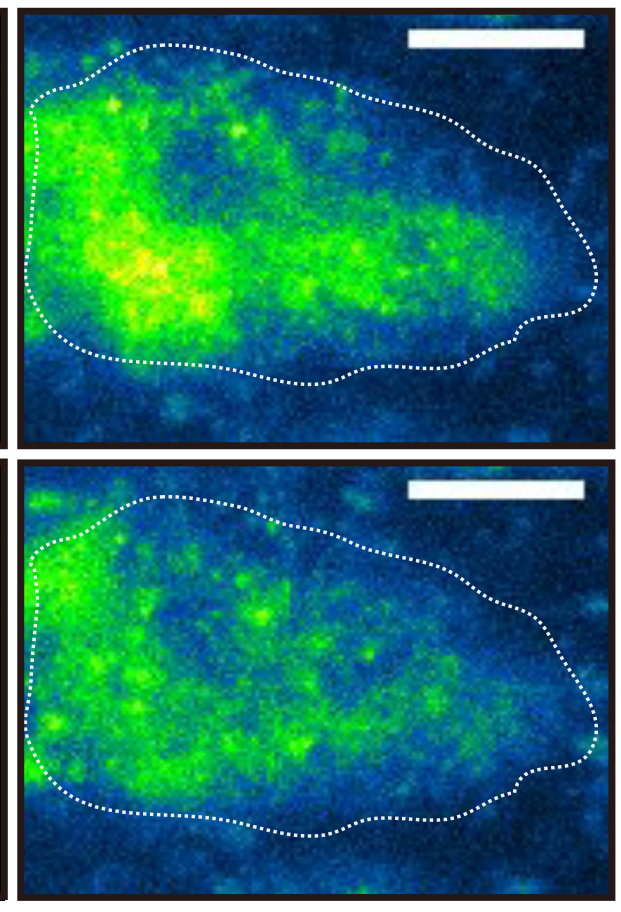

hyperpolarisation

depolarisation
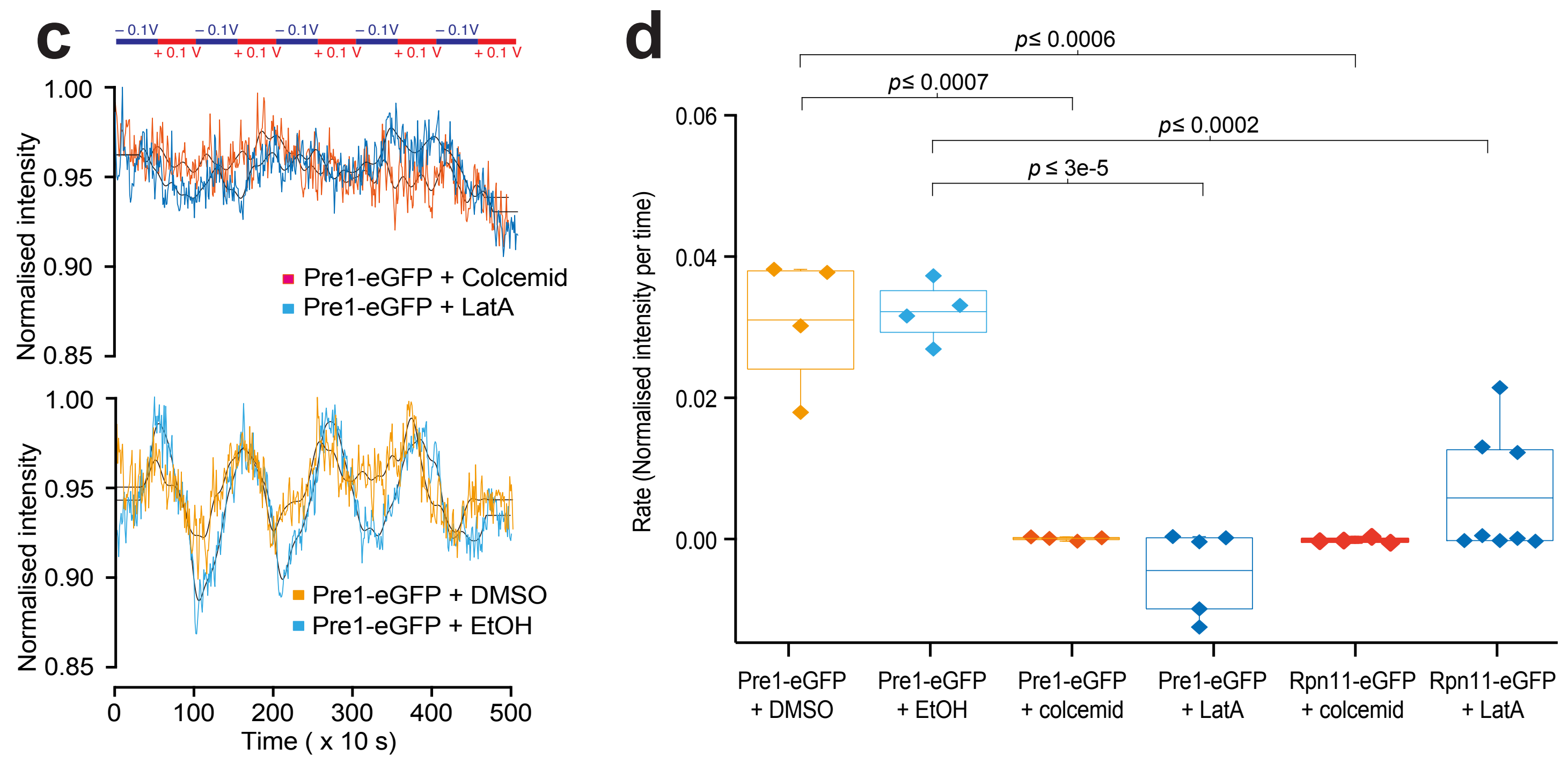


\section{Figure 5}

Rpn11-eGFP diffusion with depolymerised cytoskeleton
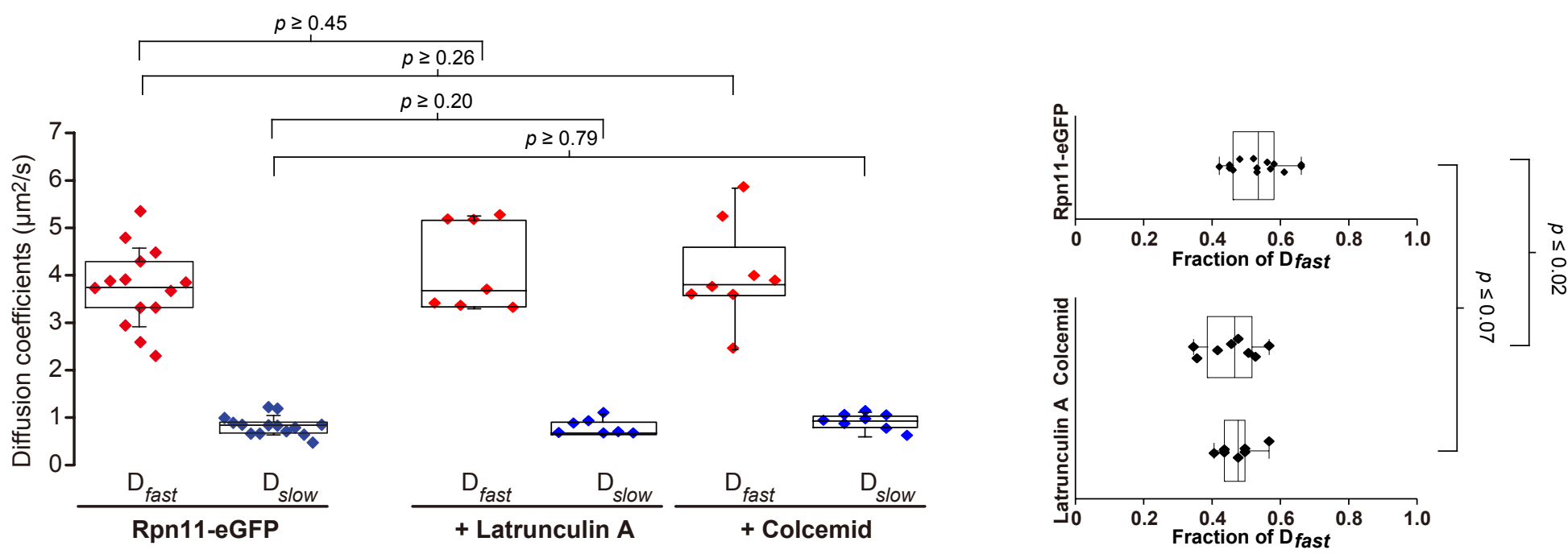

D Pre1-eGFP diffusion with depolymerised cytoskeleton
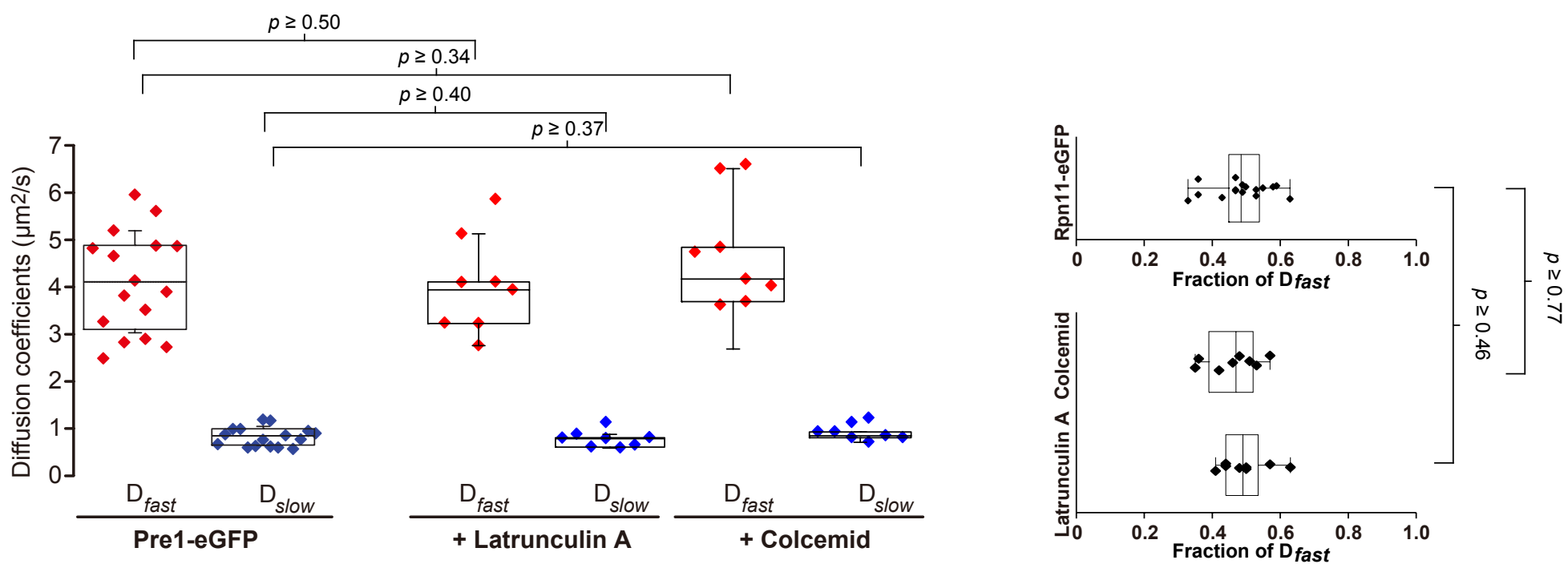


\section{Supplementary Figure 1}

a

$$
\begin{gathered}
\text { HEK293A } \\
\text { control } \\
\hline
\end{gathered}
$$

Pre1-
eGFP

Pre1mEos

beads elute beads elute beads elute

beads no antibody Pre1- Pre1eGFP mEOS

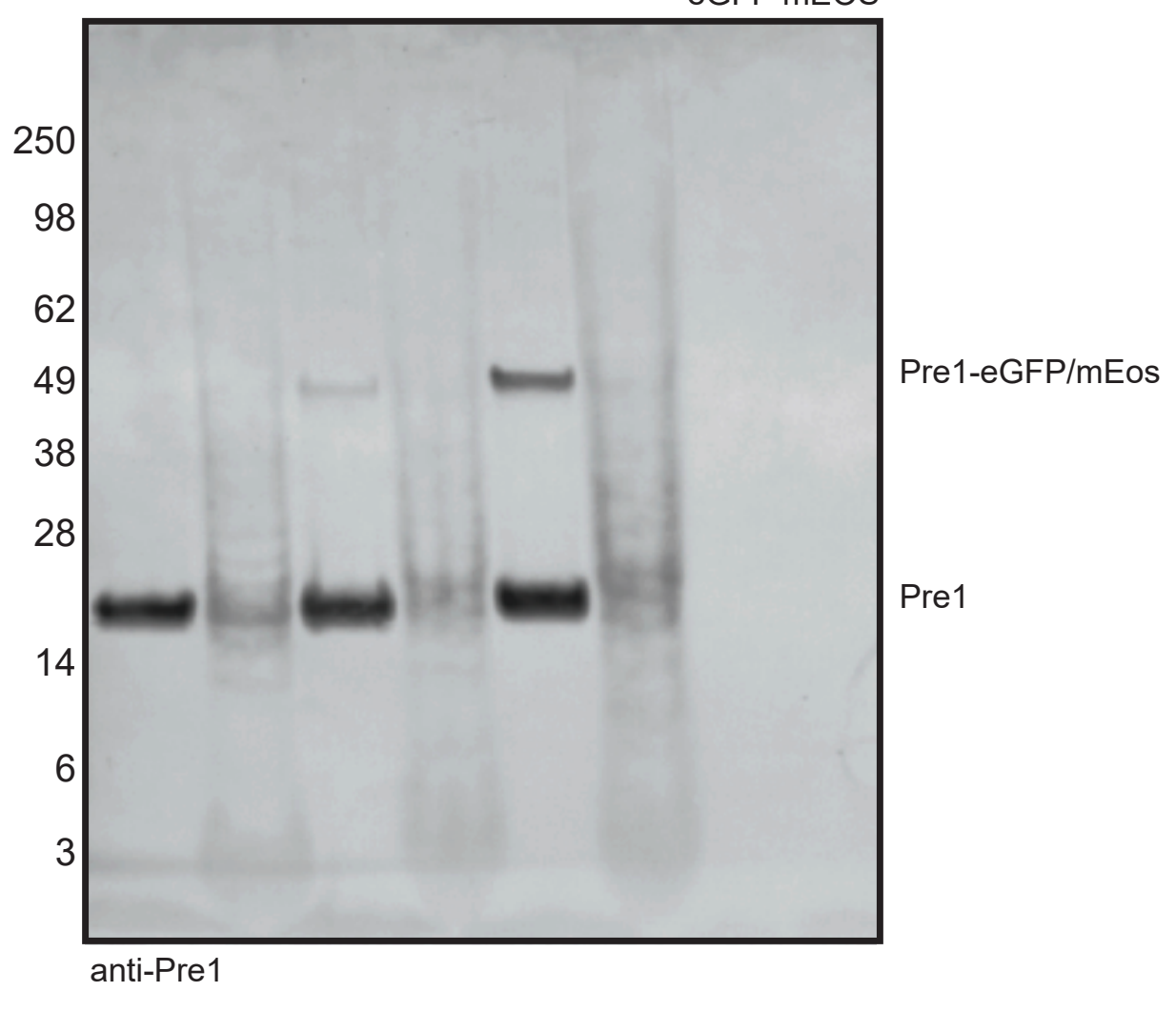

b

HEK293A control

Rpn11-
eGFP

Rpn11-

beads elute beads elute beads elute

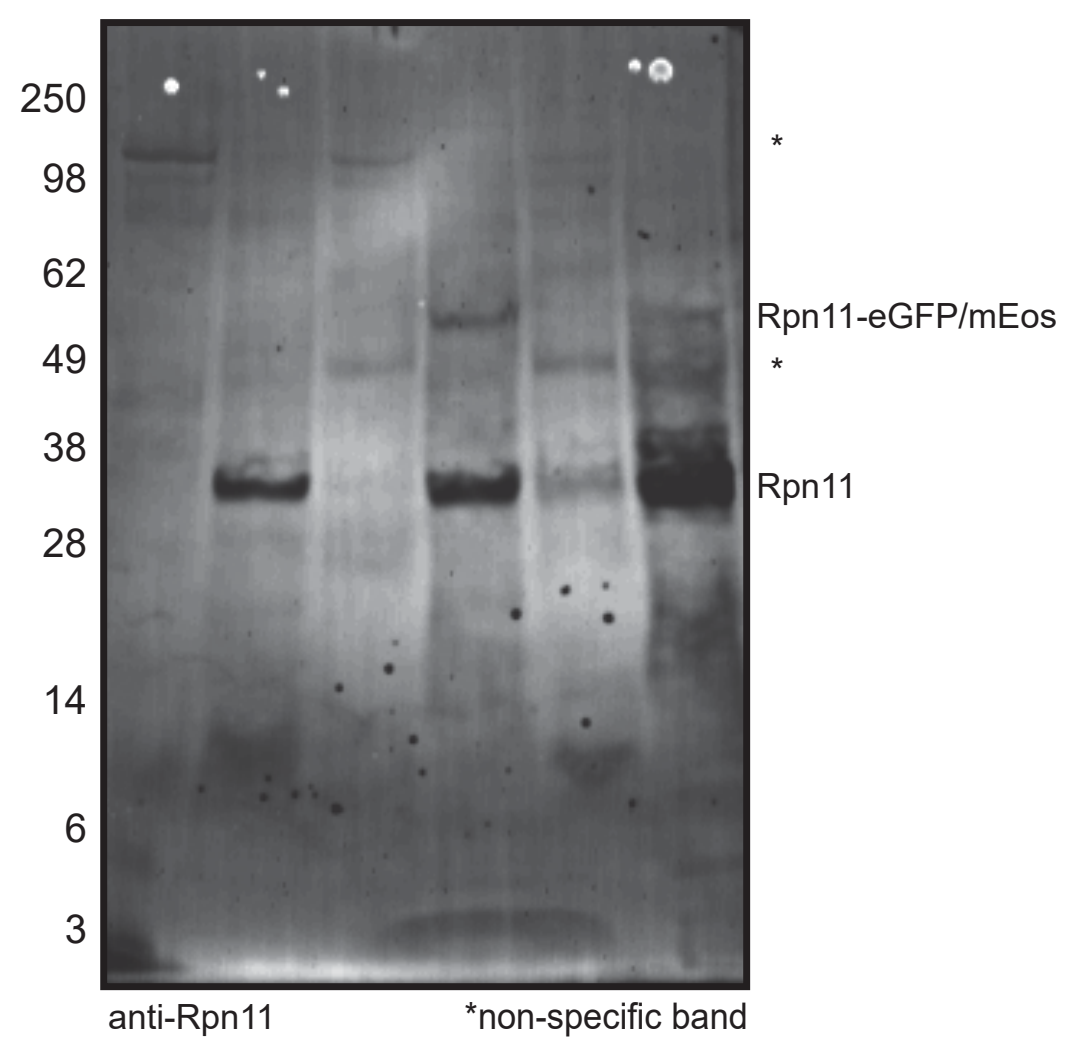




\section{Supplementary Figure 2}

bioRxiv preprint doi: https://doi.org/10.1101/487702; this version posted December 6, 2018. The copyright holder for this preprint (which was

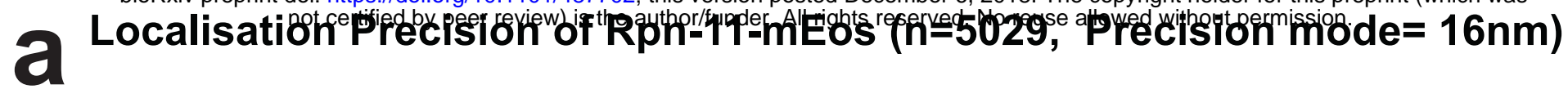

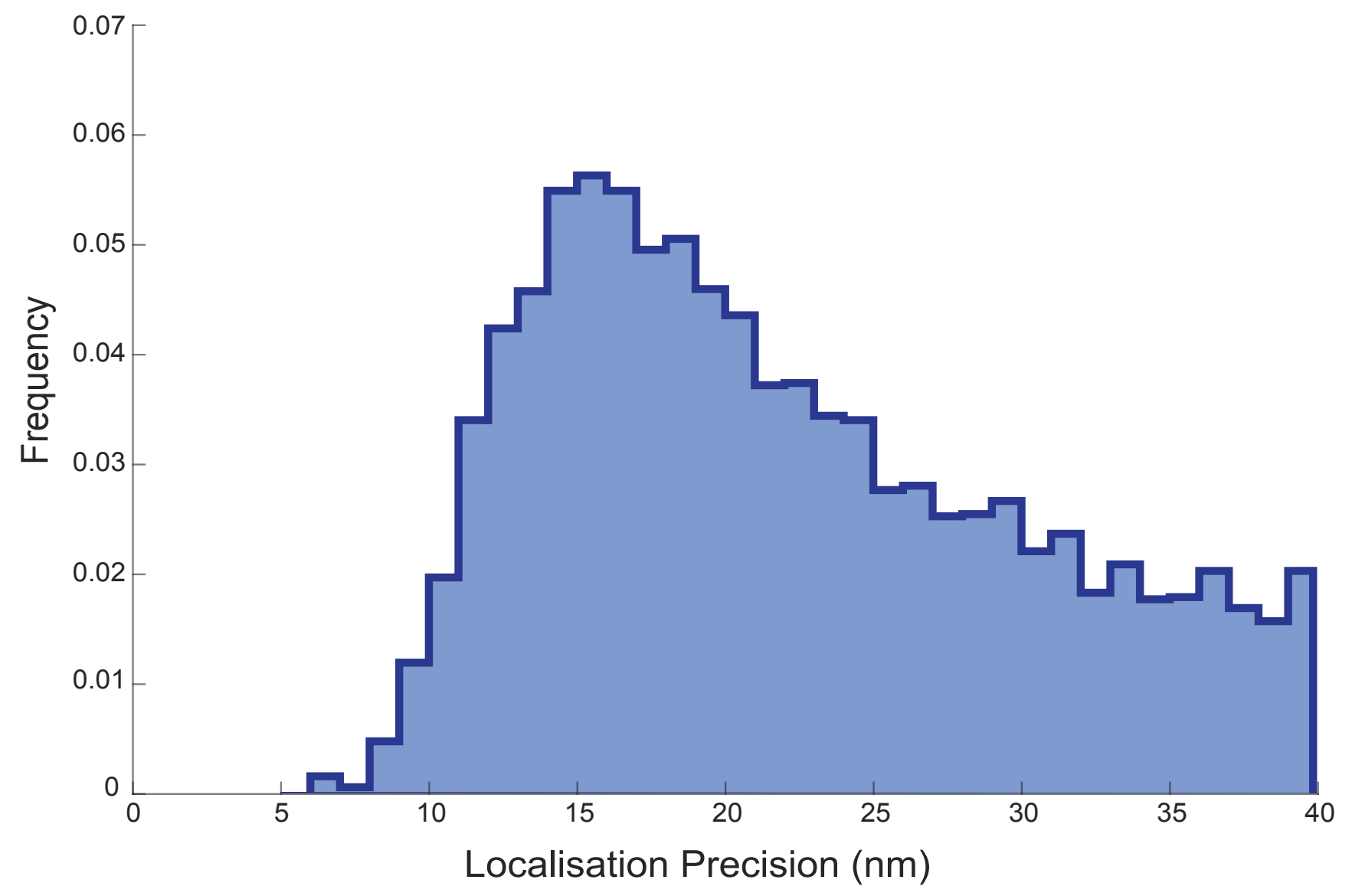

b

Localisation Precision of Pre1-mEos ( $\mathrm{n}=39458$, Precision mode= 16nm )

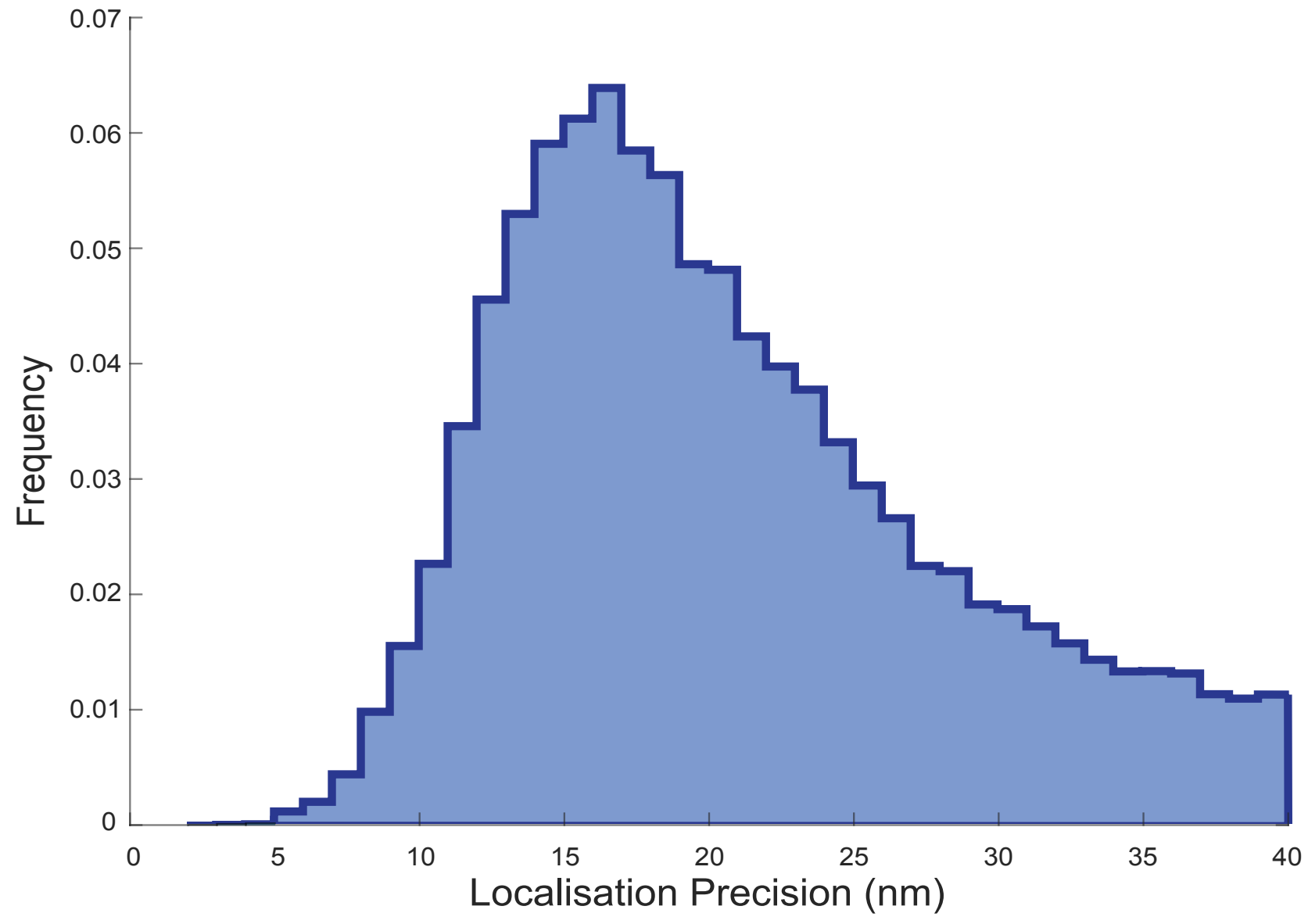




\section{Supplementary Figure 3}

bioRxiv preprint doi: https://doi.org/10.1101/487702; this version posted December 6, 2018. The copyright holder for this preprint (which was not certified by peer review) is the author/funder. All rights reserved. No reuse allowed without permission.

\section{AILO imaging of Rpn11-mEos}

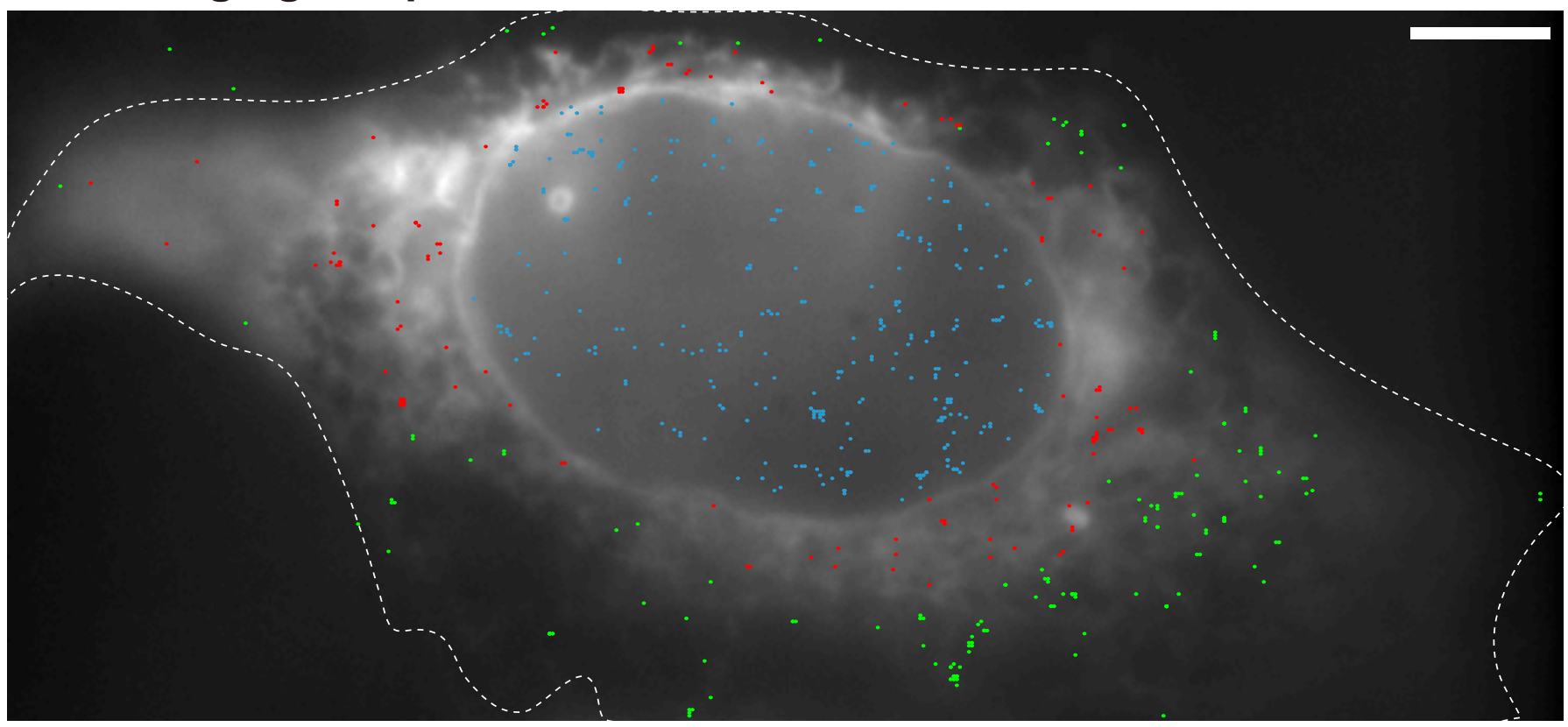

HILO imaging of Pre1-mEos

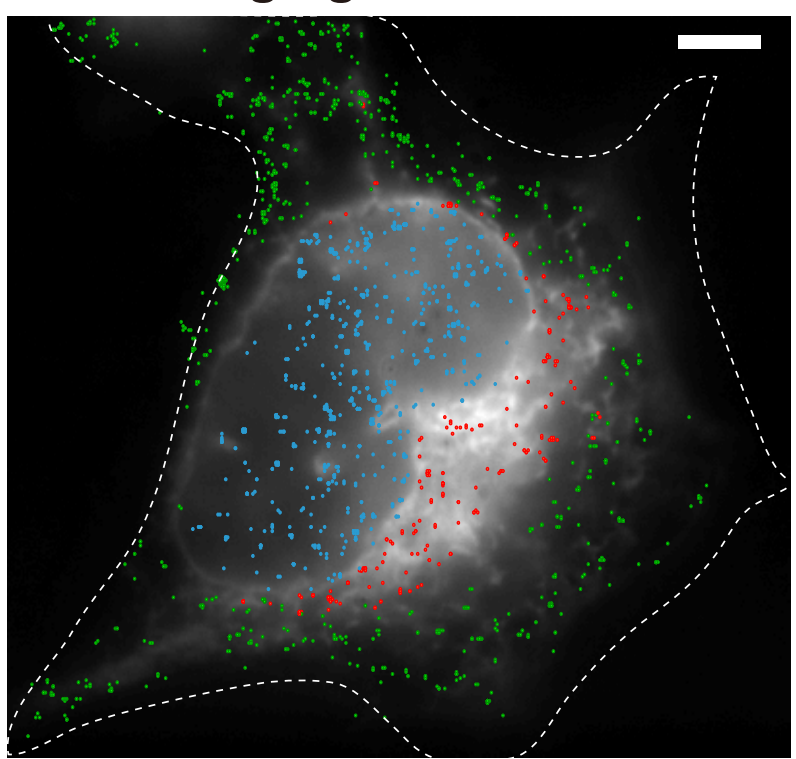

C Density of proteasome particles

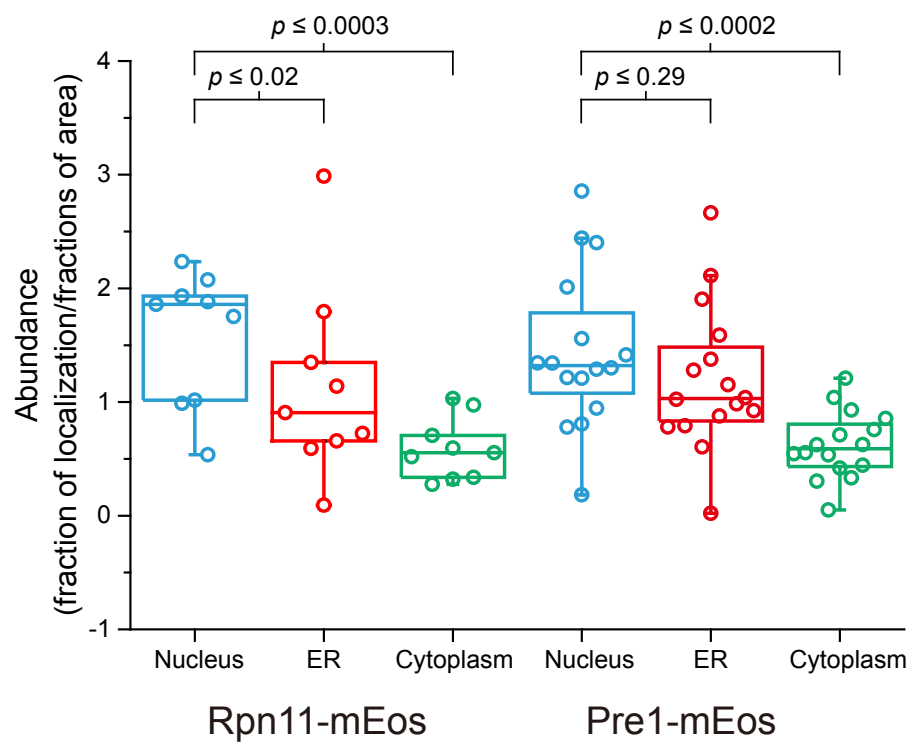




\section{Supplementary Figure 4}

bioRxiv preprint doi: https://doi.org/10.1101/487702; this Version posted December 6, 2018. The copyright holder for this preprint (which was not certified by peer review) is the author/funder. All rights reserved. No reuse allowed without permission.

\section{D imaging of Pre1-mEos}

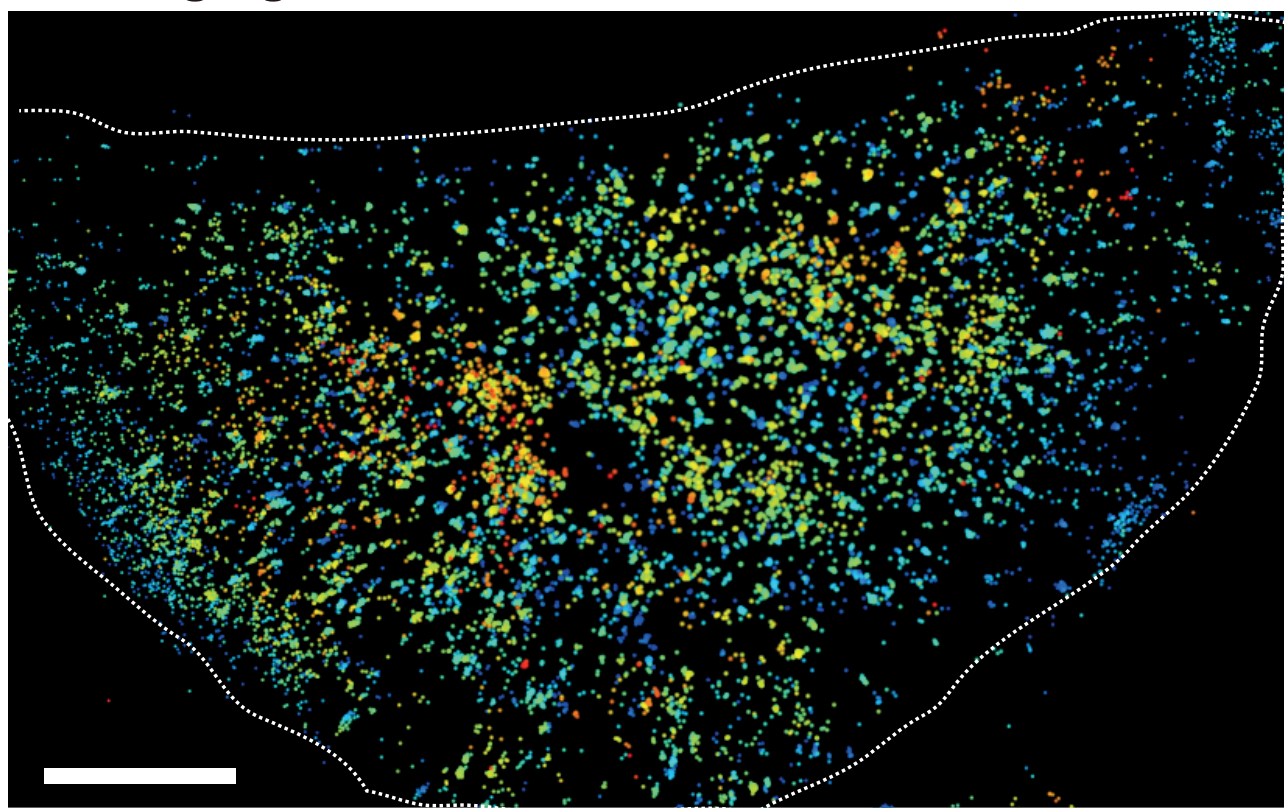

b

3D imaging of Rpn11-mEos
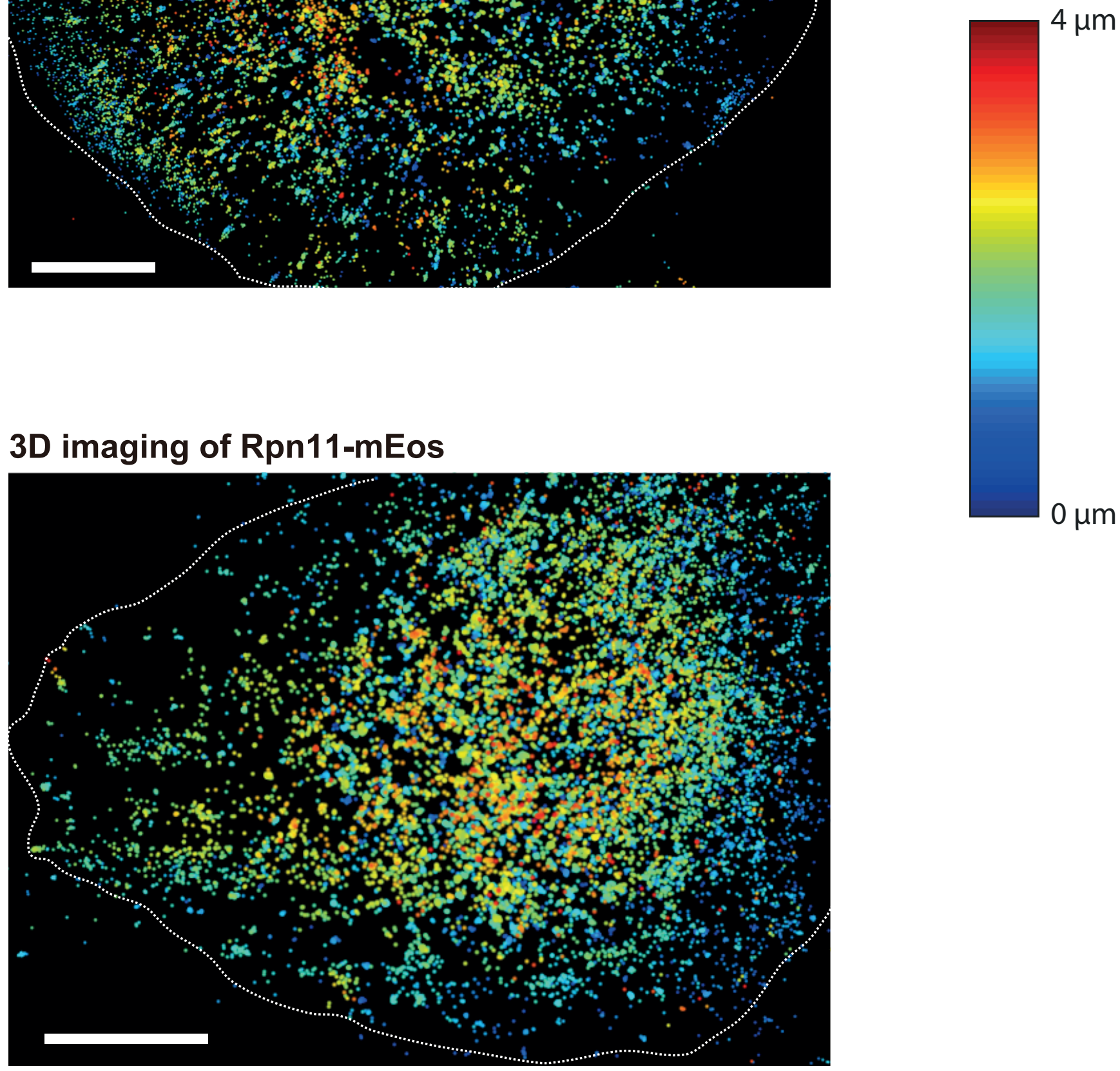


\section{Supplementary Figure 5}

\section{a TIRF imaging of Rpn11-mEos diffusion}

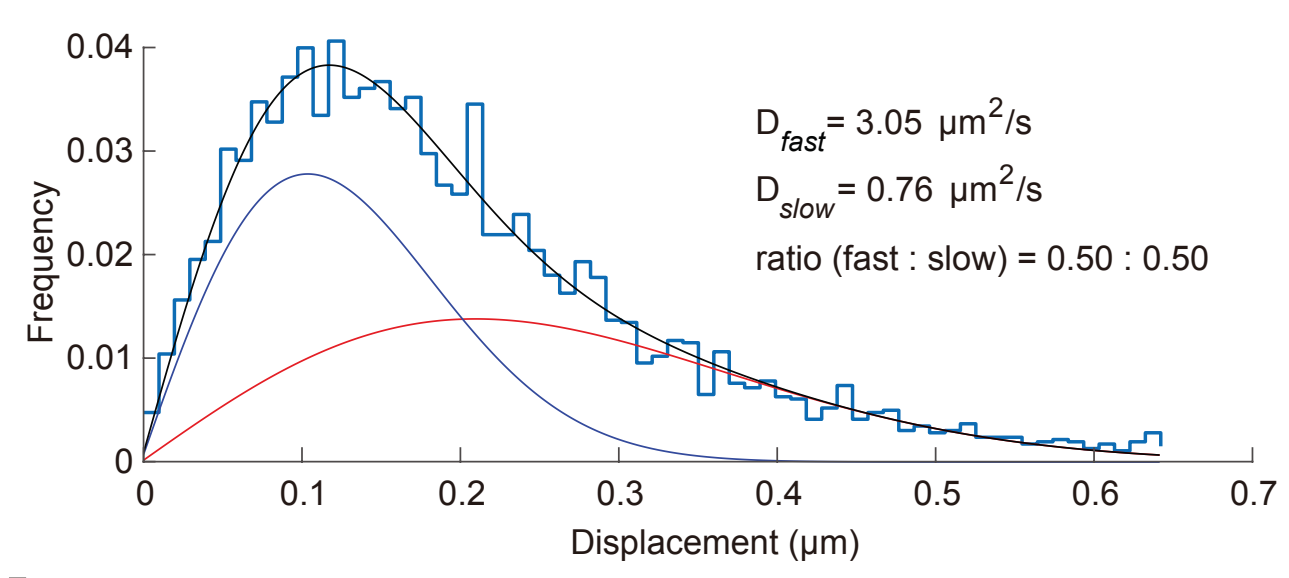

b

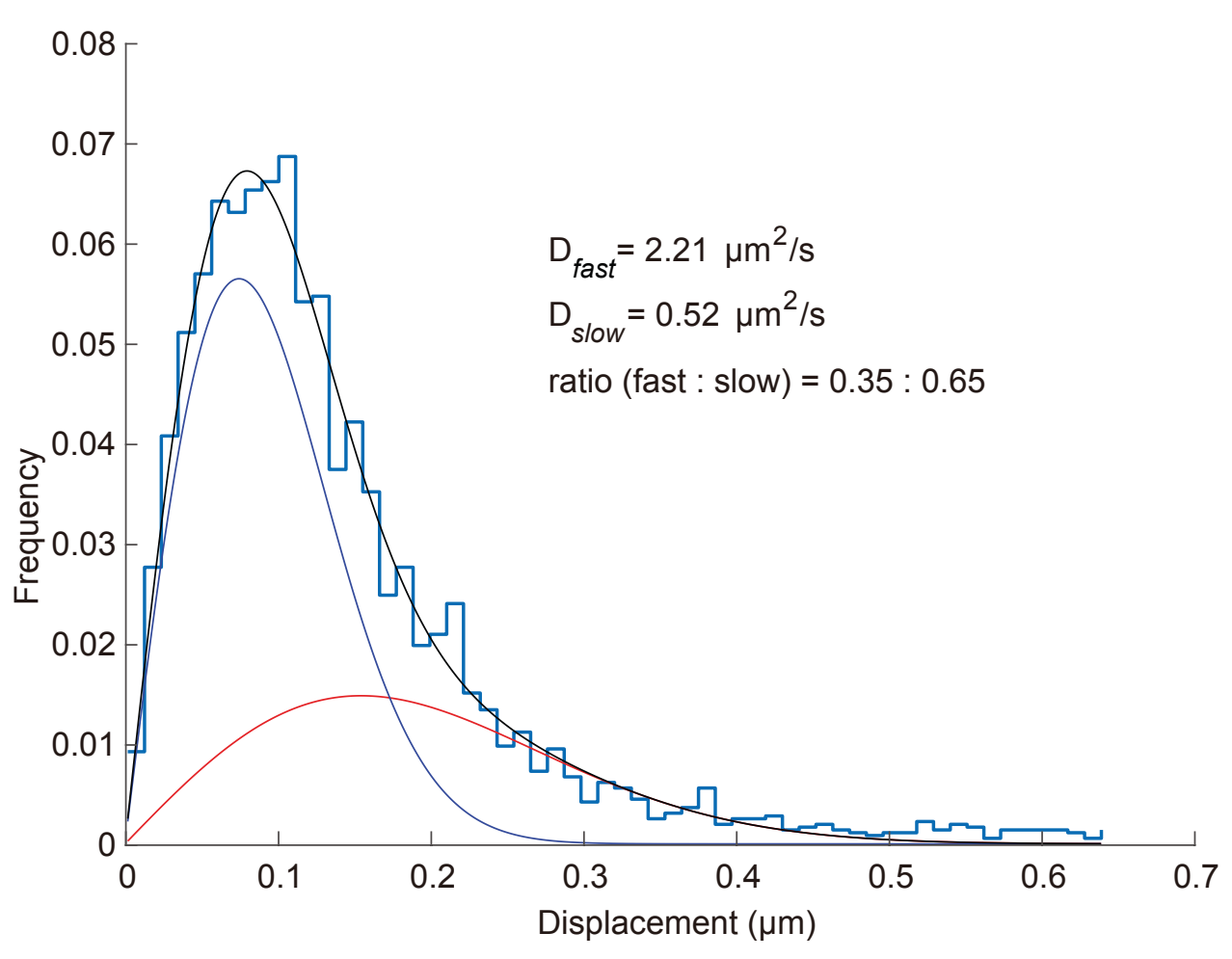

TIRF imaging of Pre1-mEos diffusion

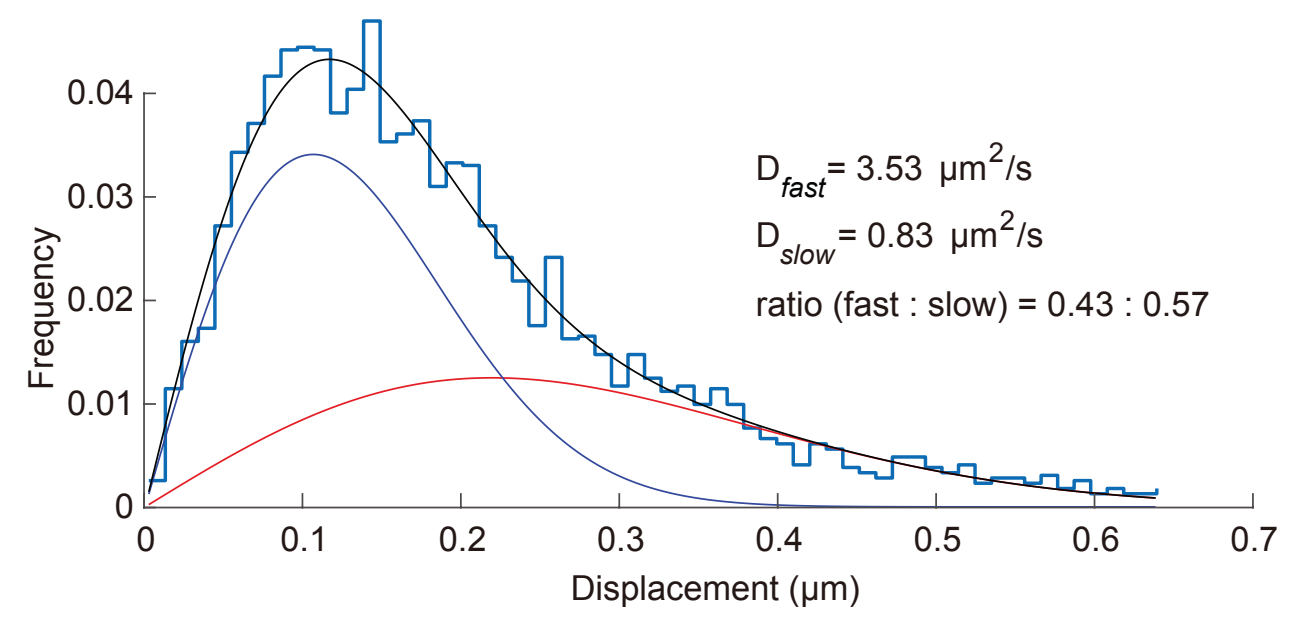

C

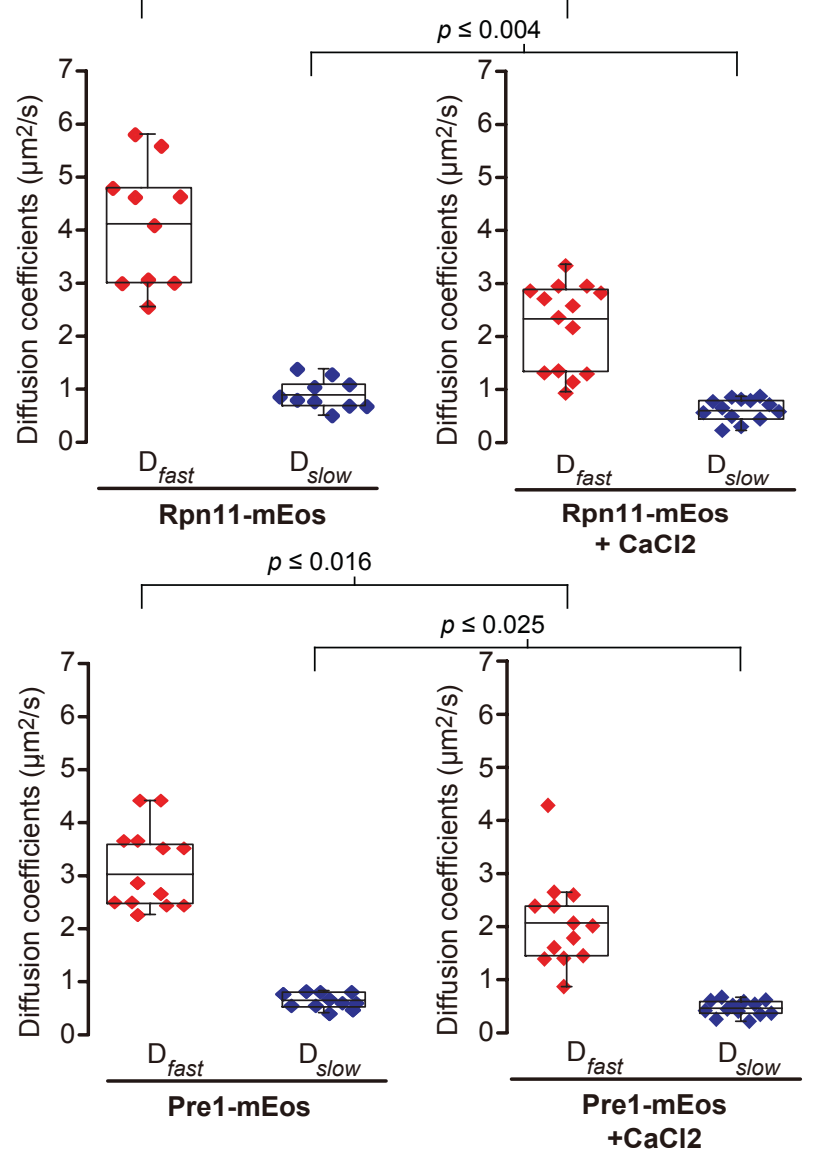

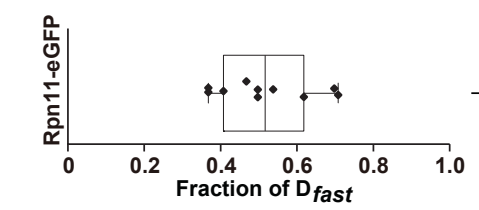
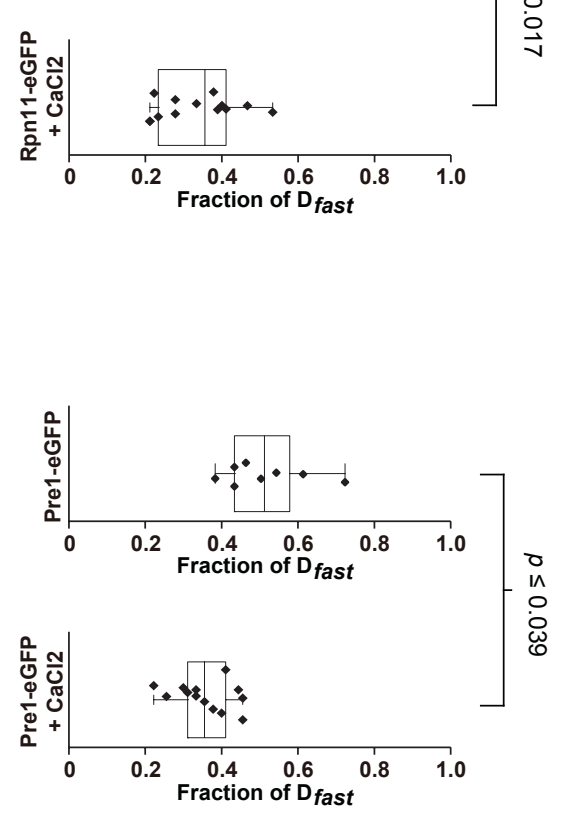


\section{Supplementary Figure 6}

a

HILO imaging of Rpn11-mEos diffusion

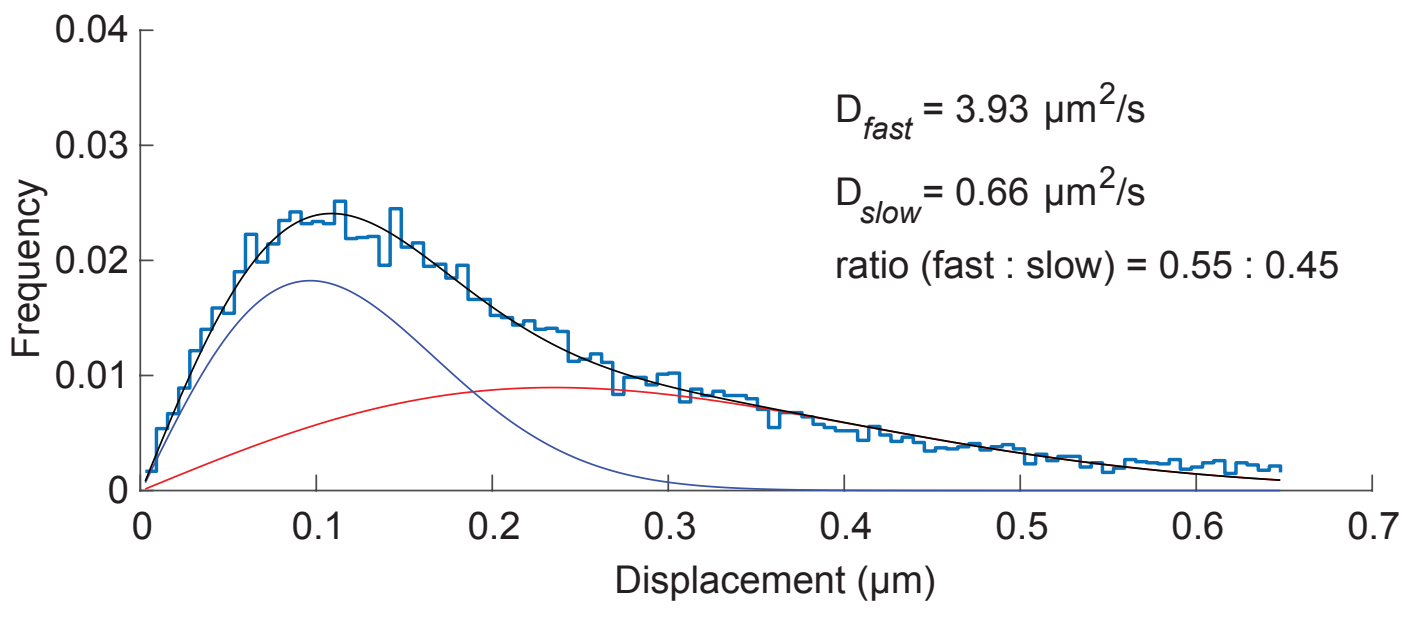

HILO imaging of Pre1-mEos diffusion

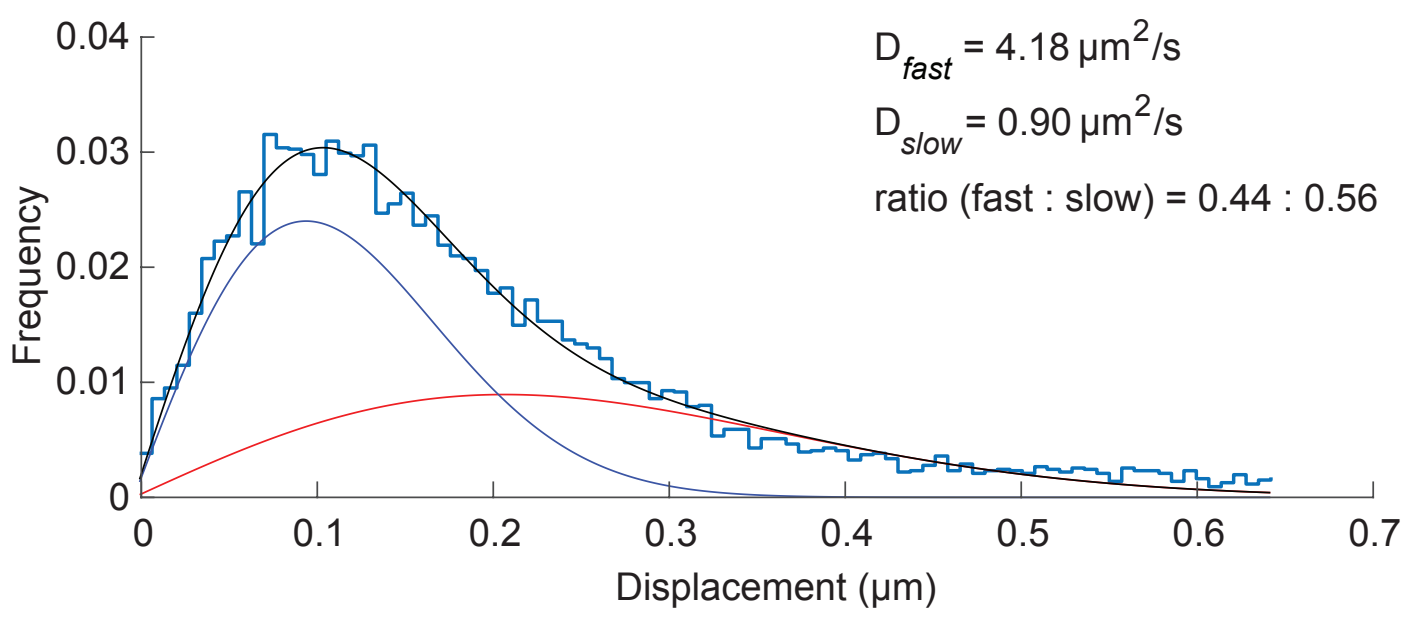




\section{Supplementary Figure 7}

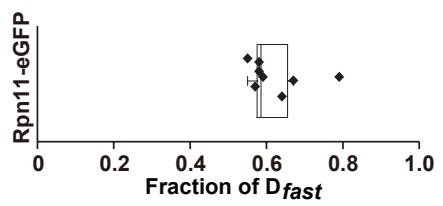

TIRF imaging of eGFP-USP21 diffusion

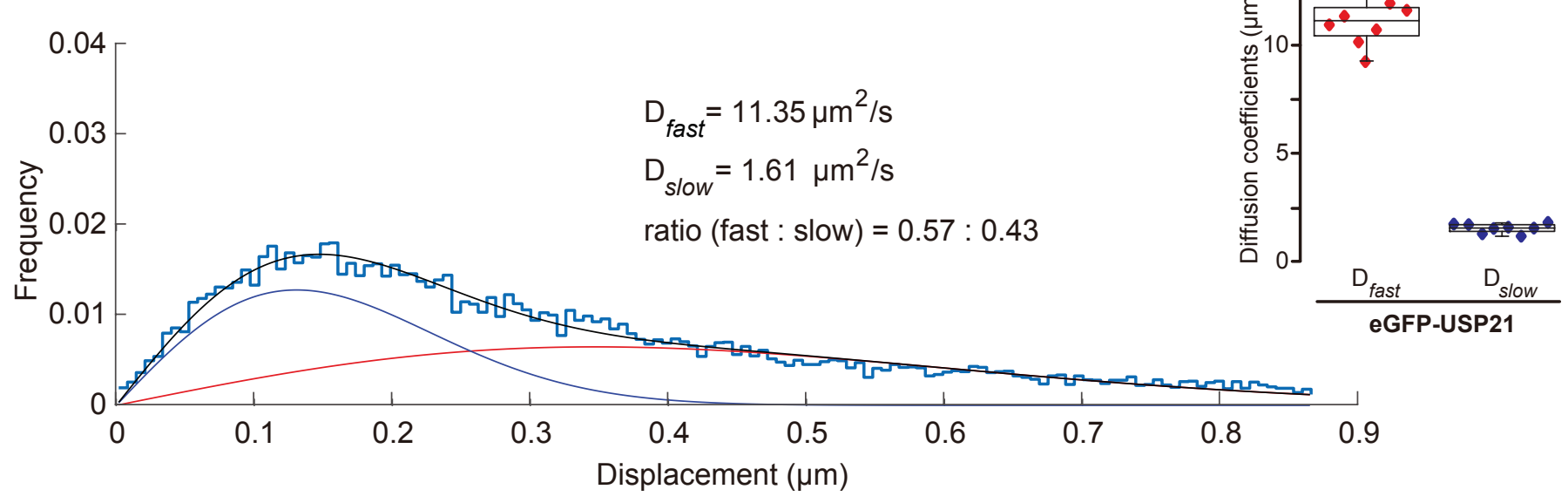




\section{Supplementary Figure 8}

\section{a}

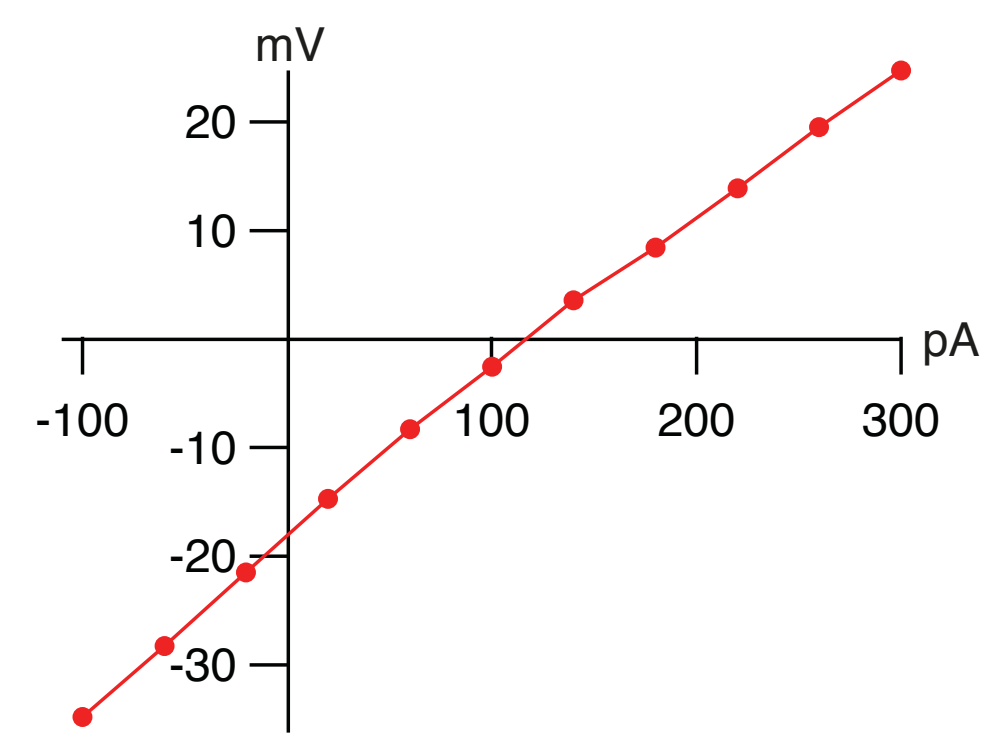

C

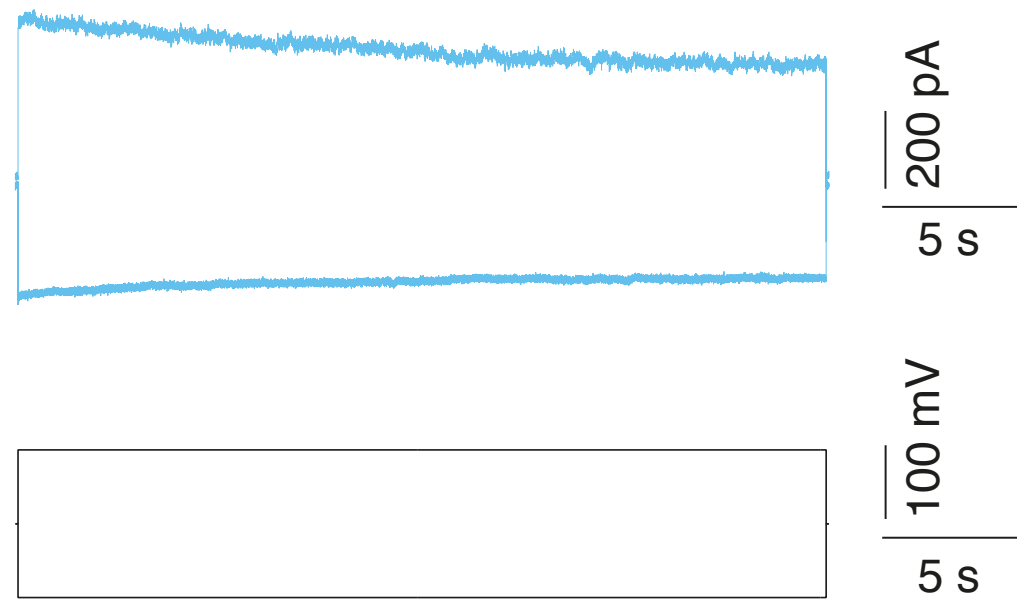

b
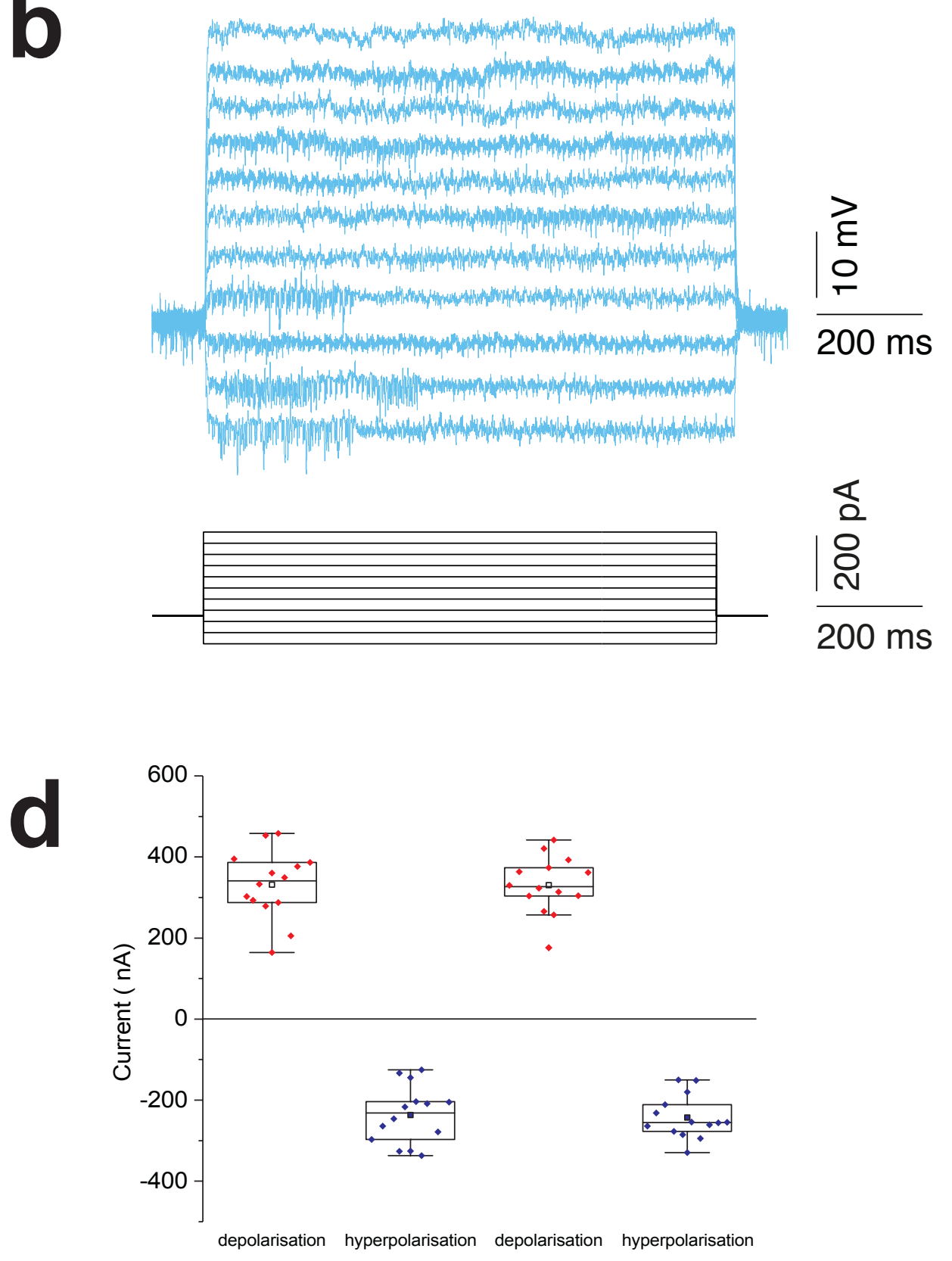

Rpn11-eGFP

Pre1-eGFP 


\section{SFigure 9}

\section{A HILO imaging with patch-clamp}
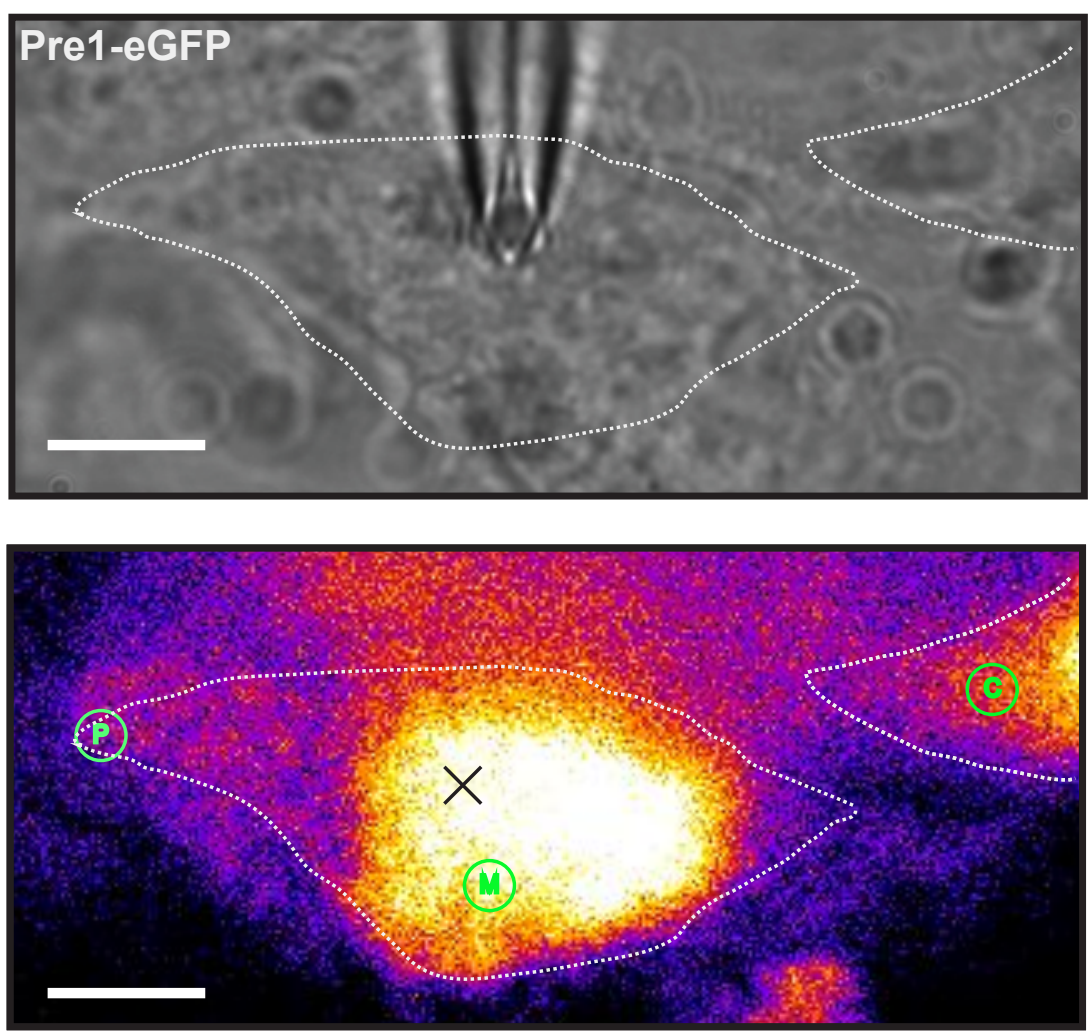

b

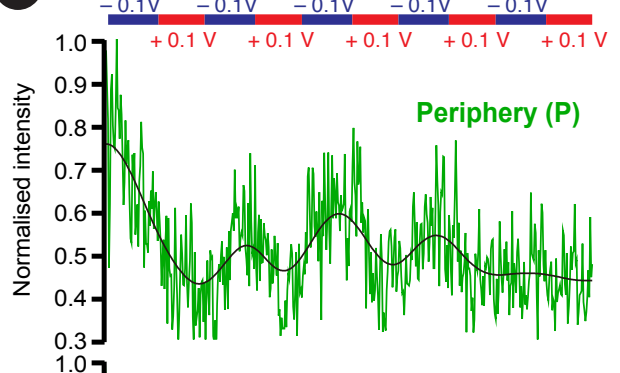

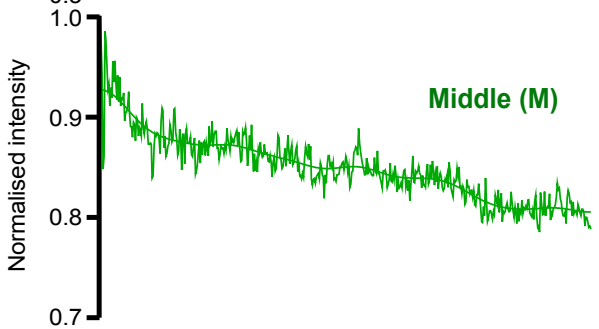

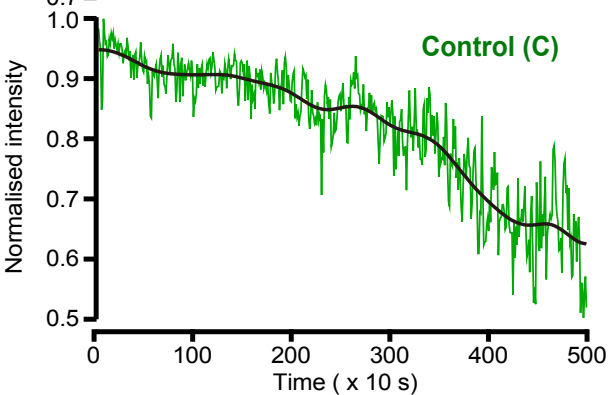

